\title{
Effect of roasting parameters on the physicochemical characteristics of high-molecular-weight Maillard reaction products isolated from cocoa beans of different Theobroma cacao L. groups
}

\author{
Joanna Oracz ${ }^{1}$ D $\cdot$ Ewa Nebesny ${ }^{1}$
}

Received: 7 March 2018 / Revised: 12 August 2018 / Accepted: 15 August 2018 / Published online: 21 August 2018

(c) The Author(s) 2018

\begin{abstract}
This study explored the effects of roasting parameters on the yield, proximal composition, free phenolic compounds content, CIE $L^{*} a^{*} b^{*}$ color characteristics, browning index, fluorescence intensity, and molecular weight distribution of high-molecular-weight (HMW) melanoidin fractions isolated by dialysis (>12.4 kDa) from cocoa beans of three Theobroma cacao L. types. The beans were roasted at four temperatures $\left(110,120,135\right.$, and $\left.150{ }^{\circ} \mathrm{C}\right)$ and two relative air humidity levels $(\mathrm{RH} 0.3$ and 5.0\%). To understand how roasting conditions affect the physicochemical properties of HMW fractions, changes in the content of carbohydrates, proteins, lipids, and phenolic compounds were determined for the tested cocoa beans. The yields of HMW products decreased after thermal processing at 110 and $120^{\circ} \mathrm{C}$, but increased at 135 and $150{ }^{\circ} \mathrm{C}$. It was found that the applied roasting temperatures and RH levels caused a significant decline in carbohydrates, proteins, and free phenolic compounds in all HMW fractions obtained from cocoa beans. Roasting led to a considerable decrease CIE lightness. In addition, degree of browning and fluorescence intensity of HMW fractions tended to increase with increasing thermal treatment temperature. High-performance size-exclusion chromatography revealed that roasting led to significant changes in the molecular weight distribution of HMW fractions.
\end{abstract}

Keywords Cocoa beans $\cdot$ Roasting $\cdot$ Maillard reaction $\cdot$ Melanoidins $\cdot$ Physicochemical properties $\cdot$ Size-exclusion chromatography

\section{Introduction}

Cocoa beans (Theobroma cacao L.) and their derivative products are highly valued by consumers around the world for their essential nutrients and bioactive phytochemicals [1]. Roasting is the principal technological operation in cocoa bean processing which leads to the development of the characteristic brown color, generates compounds responsible for the distinctive chocolate aroma and flavor, and produces a crisp texture $[2,3]$. It causes considerable changes not only to the physical and sensory properties of the beans, but also to their chemical and nutritional composition [2]. Several previous studies have indicated that temperature and

Joanna Oracz

joanna.oracz@p.lodz.pl

1 Institute of Food Technology and Analysis, Faculty of Biotechnology and Food Sciences, Lodz University of Technology, 4/10 Stefanowskiego Street, 90-924 Lodz, Poland duration of thermal processing substantially affect the character of chemical and physical changes occurring in cocoa beans. The most prominent roasting-induced chemical reactions affecting the composition of cocoa beans are Maillard reactions, caramelization, lipid oxidation, and oxidative degradation of phenolic compounds $[1,2,4]$.

Maillard reactions are initiated by interactions between carbonyl groups (mainly of reducing sugars) and the nucleophilic amino groups of amino acids, peptides, or proteins, resulting in the sugar-amine condensation and rearrangement to Amadori or Heyns products. The subsequent stages involves sugar dehydration and fragmentation, amino acid degradation, and many other fragmentation steps [5, 6]. These reactions are very complex and lead to the simultaneous or consecutive formation of highly reactive lowmolecular-weight (LMW) compounds, such as $\alpha$-dicarbonyl and $\alpha$-hydroxycarbonyl compounds, furfurals, reductones, and Strecker aldehydes [2, 5, 6]. In the final stage of Maillard reaction, condensation and polymerization reactions of the highly reactive intermediates result in the formation of 
fluorescent and brown nitrogen-containing high-molecularweight (HMW) polymers, known as melanoidins $[5,6]$. These macromolecules are not only responsible for the characteristic brown color and texture of roasted cocoa beans, but they also exhibit binding affinity for the LMW aromatic compounds released in the process of roasting. It is also well known that melanoidins display a large number of biological properties [7, 8]. Recently, these compounds have received increasing interest as functional ingredients or nutraceuticals due to their numerous health benefits, including antioxidative, antihypertensive, anti-inflammatory, antimicrobial, anticarcinogenic, antiglycative, and anticariogenic effects, as well as the ability to chelate metal ions [8-11]. Furthermore, melanoidins can act as dietary fiber in the gastrointestinal tract, promoting the growth of beneficial microorganisms such as Bifidobacteria, as well as modulating the bacterial flora of the colon $[7,8,12]$.

The biological properties of melanoidins are closely related to their structure and molecular size [13, 14]. Many previous studies have attempted to characterize the structure and composition of melanoidins in various model systems and carbohydrate-rich foods, such as coffee, barley malt, and honey $[9,12,13,15,16]$. However, due to the complexity of food systems, to date, the mechanism of melanoidin formation has not been fully elucidated. In real food systems, depending on the substrates and reaction conditions, three different types of melanoidin structures have been proposed: (1) polymers consisting of repeating furans or pyrrole units linked via polycondensation reactions [17], (2) carbohydrate skeletons built mainly from sugar degradation products polymerized through aldol-type condensation reactions and possibly linked by nitrogenous residues $[13,17]$, or (3) protein-like structures arising from crosslinks between proteins and LMW compounds formed in the advanced stages of Maillard reactions [12, 17]. In coffee, melanoidins originate from reactions between polysaccharides (galactomannans and arabinogalactans), amino acids, and proteins $[13,18]$. In recent years, it has been noted that also phenolic compounds contribute to melanoidin formation during coffee beans roasting. Unlike coffee beans and bakery products, raw cocoa beans contain relatively small amounts of reducing sugars (2\%), and only approximately $12 \%$ polysaccharides $[19,20]$. However, carbohydrates are not the only source of reactive carbonyl compounds in thermal treated foods. High-temperature processing of foods has been shown to produce lipid-derived carbonyl compounds via the lipid oxidation reactions. Recent reports indicate that interactions between lipid-derived reactive carbonyl compounds and amino acids or proteins may consist of a great number of related reactions traditionally considered exclusive to Maillard pathways [21]. Therefore, in the presence of amino acids and proteins, reactive carbonyl compounds arising from lipid peroxidation reactions might play an important role in the formation of brown HMW polymers upon cocoa bean roasting. Due to the high content of lipids (50-57\%) and proteins (10-15\%) [1, 2], cocoa beans seem to be a suitable material for investigating the formation of melanoidins in lipid-rich food systems. Although some authors have attempted to determine the yield and chemical composition of HMW melanoidins isolated from cocoaderived products [11], so far very little literature data are available on the formation of melanoidins in cocoa beans during roasting. Furthermore, no studies to date have taken into account the effect of roasting conditions, such as temperature and relative air humidity, on the physicochemical properties of HMW melanoidins isolated from cocoa beans. The chemical composition of raw cocoa beans varies widely depending on cultivation conditions and variety, and determines the most important chemical changes that occur or may occur during cocoa processing $[1,2]$. Nowadays, cocoa beans and their commercially available derivative products are obtained from three main $T$. cacao varieties, i.e., two traditional ones (Criollo, and Forastero) and their natural hybrid (Trinitario) [22]. Thus, the evaluation of changes in the phytochemical composition of three main types of cocoa beans during thermal treatment is important with a view to investigating the compounds involved in the formation of HMW Maillard reaction products.

The main objective of this work was to evaluate the effect of roasting temperature $\left(110,120,135\right.$, or $\left.150{ }^{\circ} \mathrm{C}\right)$ and relative air humidity $(0.3$ or $5.0 \%)$ on the yield, phytochemical composition, CIE $L^{*} a^{*} b^{*}$ color characteristics, browning and fluorescence intensity, and molecular weight distribution of HMW fractions isolated from Criollo, Forastero, and Trinitario beans of different origins. A complementary objective of this study was to determine the influence of different roasting conditions on the protein, carbohydrate, lipid, and phenolic compound content in cocoa beans of different T. cocoa types originating from selected geographic regions.

\section{Materials and methods}

\section{Chemicals}

Standards of fructose, glucose, sucrose, epicatechin, catechin, epigallocatechin, procyanidin $\mathrm{B} 2$, procyanidin $\mathrm{B} 1$, procyanidin $\mathrm{C} 1$, acetonitrile of HPLC grade ( $\geq 99.9 \%)$, and formic acid for LC-MS ( 98\%) were all purchased from Sigma-Aldrich (St. Louis, MO, USA). Cinnamtannin A2 was obtained from PhytoLab GmbH \& Co. KG (Vestenbergsgreuth, Germany). $N$-[3',4'-dihydroxy-(E)-cinnamoyl]3-hydroxy-L-tyrosine was purchased from Cayman Chemical Co. (Ann. Arbor, MI, USA). The standard protein mix for SEC was obtained from Phenomenex (Torrance, CA, USA). All other reagents were of analytical grade and 
were purchased from Chempur (Piekary Slaskie, Poland). Ultrapure water (resistivity $18.2 \mathrm{M} \Omega \mathrm{cm}$ ), obtained from a Milli-Q purification system (Millipore, Bedford, MA, USA), was used for all the analyses.

\section{Raw materials}

Analyses and experiments were conducted on samples of fermented and dried cocoa beans of the three main T. cacao groups: Criollo and Trinitario originating from Madagascar, and Forastero from Ghana. All cocoa beans were harvested at their technological maturity in 2013 and purchased from commercial sources.

\section{Roasting experiments}

Prior to roasting, all cocoa beans were segregated to discard impurities and chipped or broken beans. Then, the selected raw cocoa beans $(200 \mathrm{~g})$ of each group were convectively roasted in a tunnel with a forced air flow without circulation (adapted for either dry or humid air). Process air humidity was gradually increased using 4.0 MPa saturated steam from a generator. Roasting was performed at four temperatures $\left(110,120,135\right.$, or $\left.150^{\circ} \mathrm{C}\right)$ and two relative air humidity levels $(0.3$ or $5.0 \%)$. It was terminated when bean moisture dropped to $2 \%$ as determined by drying until constant weight at $103 \pm 2{ }^{\circ} \mathrm{C}$. The duration of thermal treatment was determined experimentally for each batch of cocoa beans, based on their initial water content and size. Roasting times at $150,135,120$, and $110^{\circ} \mathrm{C}$ were approximately $20,40,75$, and $85 \mathrm{~min}$, respectively. The application of higher relative air humidity prolonged the time of thermal treatment. At the end of thermal treatment, the beans were immediately cooled to approximately $20^{\circ} \mathrm{C}$ for about $10 \mathrm{~min}$. The roasted cocoa beans were kept in hermetically sealed plastic containers $(500 \mathrm{~g})$ and stored at $-20{ }^{\circ} \mathrm{C}$ for subsequent analyses. All roasting experiments were performed in duplicate for each variety used.

\section{Isolation of the high-molecular-weight fraction by dialysis}

The high-molecular-weight (HMW) fraction was obtained from raw and roasted cocoa beans by dialysis according to the methods described by Bekedam et al. [23] and Summa et al. [10] with slight modification. Prior to extraction, the cocoa beans were deshelled and ground in a laboratory mill. The cocoa nibs $(20 \mathrm{~g})$ were defatted three times with petroleum ether in an orbital shaker under constant agitation (20 min, $200 \mathrm{rpm}$ ). The resulting mixture was centrifuged at $4800 \times g$ for $15 \mathrm{~min}$, and the petroleum ether layer was discarded. Then, defatted cocoa samples were dried under a stream of nitrogen and ground to a fine powder in a laboratory mill. Batches of defatted cocoa powder $(10 \mathrm{~g})$ were extracted twice with $100 \mathrm{~mL}$ of water at $90{ }^{\circ} \mathrm{C}$ for $20 \mathrm{~min}$ in an orbital shaker $(100 \times g)$. Subsequently, pooled extracts were cooled to room temperature and filtered through Whatman no. 4 filter paper to remove insolubles. An aliquot of the filtrate $(50 \mathrm{~mL})$ was diluted to approximately $80 \mathrm{~mL}$ with water and dialyzed using a dialysis tubes (MW cut-off $>12.4$ kDa, Sigma-Aldrich, St. Louis, MO, USA) for 1 day under running tap water and for 2 days against $2000 \mathrm{~mL}$ of water at $4{ }^{\circ} \mathrm{C}$ with constant stirring. The water was changed 4-5 times until no further color was visible in the dialysate. The time required for complete dialysis was determined experimentally by high-performance size-exclusion chromatography (HPSEC). The dialysate containing LMW compounds was removed. After dialysis, the retentate containing the $\mathrm{HMW}$ fraction was frozen at $-20^{\circ} \mathrm{C}$ and lyophilized $\left(-50^{\circ} \mathrm{C}, 0.9 \mathrm{MPa}\right)$ using a DELTA 1 -24LSC Christ freeze drier (Osterode am Harz, Germany). The lyophilized isolates were weighed and HMW yield was calculated. The results were expressed as $\mathrm{g}$ per $100 \mathrm{~g}$ of cocoa beans dry weight (g/100 g DW). All lyophilized HMW samples were then stored in plastic bags at $-20{ }^{\circ} \mathrm{C}$ to prevent hydration until used.

\section{Proximate analyses}

Moisture content in cocoa beans and HMW fractions was measured using gravimetric analysis by drying at $105^{\circ} \mathrm{C}$ [24]. Protein content in cocoa beans and HMW fractions were determined pursuant to the Kjeldahl method described in AOAC 970.22, using a nitrogen-to-protein conversion factor of 6.25 [24]. The total fat content of cocoa beans was gravimetrically determined after acid hydrolysis and Soxhlet extraction with petroleum ether, according to AOAC 963.15 [24].

\section{Free sugar analysis}

The free sugar (glucose, sucrose, and fructose) composition of cocoa beans was analyzed according to the method reported by Taş and Gökmen [3], with some modifications. First, approximately $0.25 \mathrm{~g}$ sample of raw or roasted cocoa beans, previously deshelled, ground, and defatted, was subjected to direct solvent extraction with $100 \mathrm{~mL}$ of water. The mixture was shaken at $70{ }^{\circ} \mathrm{C}$ on an orbital shaker for $20 \mathrm{~min}$. The solution was allowed to cool, and then it was centrifuged at $5000 \times g$ for $5 \mathrm{~min}$. The pooled supernatants were mixed with $1 \mathrm{~mL}$ of Carrez I (potassium hexacyanoferrate (II) trihydrate) and Carrez II (zinc sulfate heptahydrate). These solutions were centrifuged at $5000 \times g$ for $5 \mathrm{~min}$. The supernatants were collected and passed through $0.45 \mu \mathrm{m}$ nylon syringe filters. Finally, the filtrate was analyzed for the content of free sugars using a UHPLC + Dionex UltiMate 3000 
system (Thermo Fisher Scientific Inc., Waltham, MA, USA) equipped with a refractive index detector (Shimadzu) and an Asahipak NH2P-50 4E column $(4.6 \times 150 \mathrm{~mm}, 5.0 \mu \mathrm{m}$ particle size; Shodex, Japan). Isocratic elution was carried out with acetonitrile/water (70/30, v/v) as the mobile phase. The flow rate and column temperature were set at $1.0 \mathrm{~mL} / \mathrm{min}$ and $30{ }^{\circ} \mathrm{C}$, respectively. Glucose, sucrose, and fructose were identified by comparing their retention times with authentic standards. Quantification was carried out using an external standard method. All measurements were done in triplicate and results were expressed as g/100 g DW.

\section{Total carbohydrate analysis}

Total carbohydrate content in cocoa beans and HMW fractions was determined after two-step sulfuric acid hydrolysis [25]. Briefly, $25 \mathrm{mg}$ samples were weighed into glass vials and $72 \% \mathrm{w} / \mathrm{w} \mathrm{H}_{2} \mathrm{SO}_{4}$ was added. The vials were capped and placed in a Reacti-Block aluminum block within a ReactiTherm III Heating/StirringModule (Thermo Fisher Scientific, Rockford, IL, USA) and left at $37{ }^{\circ} \mathrm{C}$ for $60 \mathrm{~min}$ with constant stirring $(600 \mathrm{rpm})$. Then, the reaction mixture was diluted with water to $4 \% \mathrm{w} / \mathrm{w}_{2} \mathrm{SO}_{4}$, and hydrolysis was continued at $120{ }^{\circ} \mathrm{C}$ for $40 \mathrm{~min}$ with constant stirring (600 rpm). After hydrolysis, samples were cooled immediately to room temperature and an aliquot $(0.6 \mathrm{~mL})$ was mixed with $1.4 \mathrm{~mL}$ of acetonitrile. The mixture was shaken vigorously and filtered through $0.45 \mu \mathrm{m}$ nylon syringe filters, and the supernatants were analyzed by HPLC as described above. Total carbohydrate content was quantified as glucose equivalents using external calibration curves of authentic standards. All measurements were done in triplicate with the results expressed as $\mathrm{g} / 100 \mathrm{~g} \mathrm{DW}$.

\section{Determination of phenolic compounds}

Phenolic compounds (i.e., monomeric flavan-3-ols, procyanidins, and phenolic acid derivatives) were extracted from raw and roasted cocoa beans using the procedure reported by Oracz et al. [26].

The free phenolic components remaining in HMW fractions were determined according to Liu et al. [27], with slight modifications. Approximately $20 \mathrm{mg}$ cocoa melanoidin samples were weighed in $1.5 \mathrm{~mL}$ centrifuge tubes and dissolved in water (concentration of $20 \mathrm{mg} / \mathrm{mL}$ ). Then, the samples were centrifuged at $4000 \times g$ for $10 \mathrm{~min}$, the supernatants were filtered through $0.20 \mu \mathrm{m}$ nylon syringe filters, and the filtrates were analyzed using a UHPLC-DAD-MS/ MS instrument.

The phenolic composition of the studied cocoa beans and their HMW fractions was quantified using a UHPLC + Dionex UltiMate 3000 system (Thermo Fisher Scientific Inc., Waltham, MA, USA) equipped with a
UV-Vis diode array detector and a Q-Exactive Orbitrap mass spectrometer (Thermo Scientific, Hudson, NH, USA). Samples $(10 \mu \mathrm{L})$ were injected on an Accucore ${ }^{\mathrm{TM}} \mathrm{C} 18$ column $(3.0 \times 150 \mathrm{~mm}, 2.6 \mu \mathrm{m}$ particle size; Thermo Scientific, PA, USA) thermostated at $30{ }^{\circ} \mathrm{C}$. The mobile phases were eluent A, formic acid/water $(0.1 / 99.1, \mathrm{v} / \mathrm{v})$, and eluent B, acetonitrile/water/formic acid (80/19.98/0.02, v/v/v). The flow rate was $0.3 \mathrm{~mL} / \mathrm{min}$ and the gradient was as follows: 0-5 min, 5\% B; 5-6 min, 5-8\% B; 6-25 min, 8-15\% B; 25-30 min, 15-20\% B; 30-35 min, 20-25\% B; 35-38 min, 25-30\% B; 38-45 min, 30-85\% B; 45-52 min, 85-5\% B; 52-62 min, 5\% B. UV-Vis detection was performed at $280 \mathrm{~nm}$ for monomeric flavan-3-ols and procyanidins and at $320 \mathrm{~nm}$ for $N$-phenylpropenoyl-L-amino acids. In the ESI-MS system, the capillary and heater gas temperature were 320 and $400^{\circ} \mathrm{C}$, respectively. The ESI source was operated in the negative ion mode. Capillary voltage was set to $4.5 \mathrm{kV}$. Nitrogen was used both as nebulizer gas and collision gas. The collision energy was $20 \mathrm{eV}$. Full-scan MS and target MS2 spectral data were acquired over a range from $\mathrm{m} / \mathrm{z} 50$ to 1000. Instrument control, data acquisition, and evaluation were done with Q-Exactive Tune 2.1, Chromeleon 6.8 Chromatography Data System, and Thermo Xcalibur 2.2 software, respectively. Individual phenolic compounds were identified by comparing retention times, UV-Vis absorbance spectra, full-scan mass spectra, and MS/MS fragmentation patterns with their corresponding standards analyzed under identical conditions and the previous literature reports [26, 28]. Quantifications of these compounds were carried out using external standards. The concentration of individual flavan-3-ols was determined based on peak area and calibration curves derived from corresponding reference compounds. For the quantification of $\mathrm{N}$-phenylpropenoyl-L-amino acids, the calibration curves of $N$-[3', $4^{\prime}$-dihydroxy-(E)-cinnamoyl]3-hydroxy-L-tyrosine (trans-clovamide) were used.

\section{Estimation of molecular weight distribution of high-molecular-weight fractions}

The molecular weight distribution of HMW isolates from raw and roasted cocoa beans was determined by high-performance size-exclusion chromatography (HPSEC) using an UHPLC + Dionex UltiMate 3000 system (Thermo Fisher Scientific Inc., Waltham, MA, USA) and a PolySep ${ }^{\mathrm{TM}}$ GFC-P4000 column $(300 \times 7.8 \mathrm{~mm}$ i.d., with exclusion limits of 3-400 kDa) with a PolySep ${ }^{\text {TM }}$-GFC-P guard column $(35 \times 7.8 \mathrm{~mm}$ i.d.) from Phenomenex (Torrance, CA, USA). Prior to analysis, samples of lyophilized HMW fractions were dissolved in an elution buffer consisting of $10 \mathrm{mM}$ ammonium acetate (concentration of $1 \mathrm{mg} / \mathrm{mL}$ ) and passed through $0.45 \mu \mathrm{m}$ nylon syringe filters. The column was eluted with $10 \mathrm{mM}$ ammonium acetate at a flow rate of $0.5 \mathrm{~mL} / \mathrm{min}$. The volume of injected samples was $5 \mu \mathrm{L}$. 
The column temperature was $25{ }^{\circ} \mathrm{C}$. Chromatograms were recorded at wavelengths of 280 and $420 \mathrm{~nm}$. The column was calibrated using protein standards (bovine thyroglobulin, $670 \mathrm{kDa}$; IgA, $300 \mathrm{kDa}$; IgG, $150 \mathrm{kDa}$; ovalbumin, $44 \mathrm{kDa}$; myoglobin, $17 \mathrm{kDa}$ ). The calibration curve showed the relationship between the log molecular weight of the standards and their elution times $\left(R^{2}=0.997\right)$. Data acquisition and processing were performed using Chromeleon 6.8 Chromatography Data System software (Thermo Fisher Scientific Inc., Waltham, MA, USA).

\section{$\mathrm{CIE} L^{*} a^{*} b^{*}$ color measurements of high-molecular-weight fractions}

Color evaluation of HMW isolates from raw and roasted cocoa beans was performed using a Minolta CR-400 Chroma meter with Spectra Magic NX 1.3 software (Konica Minolta, Osaka, Japan), and the results were expressed in accordance with the CIE $L^{*} a^{*} b^{*}$ system with CIE Standard Illuminant D65 as a light source. The CIE (Commission International de l'Eclairage) color values were $L^{*}$ (luminosity, from 0 -black to 100 -white), $a^{*}$ [from $(-50)$-green to 50 -red] and $b^{*}$ (from (-50)-blue to 50-yellow), were determined. Prior to measurements, the instrument was calibrated with a CR-A43 standard calibration white plate $\left(L^{*}=93.80\right.$; $\left.a^{*}=0.3156 ; b^{*}=0.3319\right)$.

\section{Browning index determination of high-molecular-weight fractions}

The browning index of HMW isolates from raw and roasted cocoa beans was estimated according to the protocol described by Rufián-Henares and Morales [29], with a slight modification. Prior to determination, each lyophilized HMW sample was dissolved in water (concentration of $1.0 \mathrm{mg} / \mathrm{mL}$ ) and filtered through a $0.45 \mu \mathrm{m}$ nylon membrane filter. The absorbance of HMW solutions was measured at $420 \mathrm{~nm}$ in a quartz cuvette with a $10 \mathrm{~mm}$ light path length using a UV-1800 spectrophotometer (Shimadzu, Kyoto-Japan), and data were acquired with UVProbe software. The results were expressed as arbitrary absorbance units.

\section{Fluorescence intensity determination of the high-molecular-weight fractions}

The fluorescence intensity of HMW isolates from raw and roasted cocoa beans was measured at an excitation wavelength of $347 \mathrm{~nm}$ and emission wavelength of $421 \mathrm{~nm}$ using an RF 5301PC fluorescence spectrophotometer (Shimadzu, Tokyo, Japan) according to the procedure reported by Dong et al. [30], with a slight modification. Prior to determination, each lyophilized HMW sample was dissolved in water (concentration of $1.0 \mathrm{mg} / \mathrm{mL}$ ), filtered through a $0.45 \mu \mathrm{m}$ nylon membrane filter and diluted $(1: 10, \mathrm{v} / \mathrm{v})$ with $10 \mathrm{mM}$ phosphate buffer ( $\mathrm{pH}$ 7.0).

\section{Statistical analysis}

All analyses were performed in triplicate for each sample and the results were expressed as means \pm standard deviations. Data were subjected to the analysis of variance (oneway ANOVA) after testing for normal distribution (Shapiro-Wilk test) and equality of variances (Levene's test) using STATISTICA 11 software (StatSoft Inc., Tulsa, USA). Tukey's honest significant difference post hoc test was performed to detect significant differences between means. The differences were considered to be significant at $p<0.05$. In addition, Pearson correlations were used to investigate relationships between the investigated parameters.

\section{Results and discussion}

\section{Effect of roasting conditions on chemical composition of cocoa beans}

Table 1 shows the proximate composition of raw and roasted beans of the three evaluated cocoa types. Proximate composition was expressed as percentage (g per $100 \mathrm{~g}$ ) on a dry weight basis (DW). Total carbohydrates and lipids in raw samples were found to vary from 5.56 to $6.70 \%$ and from 57.80 to $59.54 \%$, respectively, being significantly higher $(p<0.05)$ in Criollo beans from Madagascar than in Forastero beans from Ghana and Trinitario beans from Madagascar. On the other hand, protein content was the highest $(p<0.05)$ in the Forastero $(17.44 \%)$, followed by Criollo $(16.49 \%)$ and Trinitario (16.16\%). These differences may be explained by several factors, such as plant variety, geographic region, ripening degree, and post-harvest conditions $[1,19]$.

As regards free sugar content (Fig. 1), the results ranged from $0.95 \mathrm{~g} / 100 \mathrm{~g} \mathrm{DW}$ for Trinitario to $1.15 \mathrm{~g} / 100 \mathrm{~g} \mathrm{DW}$ for Forastero, with the differences being statistically significant $(p<0.05)$. The most abundant free sugar in raw beans was fructose; its content ranged from $0.70 \mathrm{~g} / 100 \mathrm{~g}$ DW for Criollo to $0.75 \mathrm{~g} / 100 \mathrm{~g}$ DW for Forastero. Glucose and sucrose concentrations were considerably lower at $0.16-0.22 \mathrm{~g} / 100 \mathrm{~g}$ DW and 0.08-0.18 g/100 g DW, respectively. Similar concentrations of lipids, proteins, and free sugars in cocoa beans were found by Redgwell, Trovato, and Corti [20], and Efraim et al. [31]. However, other authors reported higher levels of total carbohydrates, which may be attributable to differences not only in the tested materials, but also in the analytical procedures applied.

The present results indicate that roasting significantly $(p<0.05)$ affected the composition of cocoa beans, with 
Table 1 Proximate composition and HMW yields (\%, dry weight) of raw and roasted cocoa beans of Criollo, Forastero, and Trinitario groups originating from various geographical regions

\begin{tabular}{|c|c|c|c|c|c|c|}
\hline \multirow[t]{2}{*}{ Cultivars (country of origin) } & \multicolumn{2}{|c|}{ Roasting conditions } & \multirow[t]{2}{*}{ Carbohydrates (\%) } & \multirow[t]{2}{*}{ Lipids (\%) } & \multirow[t]{2}{*}{ Proteins (\%) } & \multirow[t]{2}{*}{ HMW yields (\%) } \\
\hline & Temp. $\left({ }^{\circ} \mathrm{C}\right)$ & RH (\%) & & & & \\
\hline \multirow[t]{9}{*}{ Criollo (Madagascar) } & Unroasted & & $6.70 \pm 0.04^{\mathrm{f}, \mathrm{C}}$ & $59.54 \pm 0.11^{\mathrm{d}, \mathrm{C}}$ & $16.49 \pm 0.10^{\mathrm{e}, \mathrm{B}}$ & $5.91 \pm 0.02^{\mathrm{c}, \mathrm{C}}$ \\
\hline & 110 & 0.3 & $6.63 \pm 0.02^{\mathrm{e}}$ & $58.35 \pm 0.14^{\mathrm{b}}$ & $14.71 \pm 0.11^{\mathrm{d}}$ & $5.45 \pm 0.03^{b}$ \\
\hline & & 5.0 & $6.68 \pm 0.03^{\mathrm{e}, \mathrm{f}}$ & $58.50 \pm 0.17^{\mathrm{b}}$ & $14.78 \pm 0.09^{\mathrm{d}}$ & $5.43 \pm 0.03^{b}$ \\
\hline & 120 & 0.3 & $6.35 \pm 0.04^{c}$ & $57.29 \pm 0.15^{\mathrm{a}}$ & $14.45 \pm 0.10^{\mathrm{c}}$ & $5.35 \pm 0.02^{\mathrm{a}}$ \\
\hline & & 5.0 & $6.50 \pm 0.03^{\mathrm{d}}$ & $58.44 \pm 0.09^{\mathrm{b}}$ & $14.53 \pm 0.08^{c}$ & $5.33 \pm 0.01^{\mathrm{a}}$ \\
\hline & 135 & 0.3 & $6.07 \pm 0.02^{\mathrm{b}}$ & $58.86 \pm 0.14^{\mathrm{c}}$ & $12.26 \pm 0.12^{\mathrm{b}}$ & $5.96 \pm 0.03^{\mathrm{c}, \mathrm{d}}$ \\
\hline & & 5.0 & $6.12 \pm 0.01^{\mathrm{b}}$ & $58.90 \pm 0.12^{\mathrm{c}}$ & $12.32 \pm 0.11^{\mathrm{b}}$ & $5.92 \pm 0.02^{\mathrm{c}, \mathrm{d}}$ \\
\hline & 150 & 0.3 & $5.85 \pm 0.02^{\mathrm{a}}$ & $58.43 \pm 0.11^{\mathrm{b}}$ & $12.02 \pm 0.10^{\mathrm{a}}$ & $6.04 \pm 0.01^{\mathrm{e}}$ \\
\hline & & 5.0 & $5.79 \pm 0.01^{\mathrm{a}}$ & $58.82 \pm 0.10^{\mathrm{c}}$ & $12.05 \pm 0.09^{\mathrm{a}}$ & $5.99 \pm 0.03^{\mathrm{d}, \mathrm{e}}$ \\
\hline \multirow[t]{9}{*}{ Forastero (Ghana) } & Unroasted & & $5.56 \pm 0.02^{\mathrm{e}, \mathrm{A}}$ & $58.92 \pm 0.12^{\mathrm{d}, \mathrm{B}}$ & $17.44 \pm 0.11^{\mathrm{g}, \mathrm{C}}$ & $5.58 \pm 0.01^{\mathrm{b}, \mathrm{B}}$ \\
\hline & 110 & 0.3 & $5.34 \pm 0.03^{\mathrm{d}}$ & $57.80 \pm 0.13^{\mathrm{b}, \mathrm{c}}$ & $16.69 \pm 0.10^{\mathrm{f}}$ & $5.32 \pm 0.03^{\mathrm{a}}$ \\
\hline & & 5.0 & $5.37 \pm 0.01^{\mathrm{d}}$ & $57.97 \pm 0.14^{\mathrm{c}}$ & $16.79 \pm 0.12^{\mathrm{f}}$ & $5.30 \pm 0.02^{\mathrm{a}}$ \\
\hline & 120 & 0.3 & $5.21 \pm 0.02^{\mathrm{c}}$ & $57.59 \pm 0.10^{\mathrm{b}}$ & $16.42 \pm 0.09^{\mathrm{e}}$ & $5.34 \pm 0.03^{\mathrm{a}}$ \\
\hline & & 5.0 & $5.24 \pm 0.03^{\mathrm{c}}$ & $57.80 \pm 0.11^{\mathrm{b}, \mathrm{c}}$ & $16.51 \pm 0.11^{\mathrm{e}}$ & $5.33 \pm 0.02^{\mathrm{a}}$ \\
\hline & 135 & 0.3 & $4.77 \pm 0.03^{b}$ & $57.28 \pm 0.13^{\mathrm{a}}$ & $15.26 \pm 0.10^{\mathrm{c}}$ & $5.61 \pm 0.03^{\mathrm{b}, \mathrm{c}}$ \\
\hline & & 5.0 & $4.82 \pm 0.02^{\mathrm{b}}$ & $57.78 \pm 0.16^{\mathrm{b}}$ & $15.45 \pm 0.13^{\mathrm{d}}$ & $5.58 \pm 0.02^{\mathrm{b}}$ \\
\hline & 150 & 0.3 & $4.65 \pm 0.01^{\mathrm{a}}$ & $57.61 \pm 0.12^{\mathrm{b}}$ & $13.64 \pm 0.12^{\mathrm{a}}$ & $5.71 \pm 0.02^{\mathrm{d}}$ \\
\hline & & 5.0 & $4.68 \pm 0.03^{\mathrm{a}}$ & $57.87 \pm 0.11^{\mathrm{c}}$ & $13.78 \pm 0.10^{\mathrm{b}}$ & $5.68 \pm 0.03^{\mathrm{c}, \mathrm{d}}$ \\
\hline \multirow[t]{9}{*}{ Trinitario (Madagascar) } & Unroasted & & $6.52 \pm 0.03^{\mathrm{e}, \mathrm{B}}$ & $57.80 \pm 0.14^{\mathrm{e}, \mathrm{A}}$ & $16.16 \pm 0.09^{\mathrm{e}, \mathrm{A}}$ & $5.35 \pm 0.01^{\mathrm{d}, \mathrm{A}}$ \\
\hline & 110 & 0.3 & $6.35 \pm 0.02^{\mathrm{d}}$ & $56.47 \pm 0.11^{\mathrm{c}, \mathrm{d}}$ & $14.95 \pm 0.10^{\mathrm{d}}$ & $5.17 \pm 0.02^{\mathrm{c}}$ \\
\hline & & 5.0 & $6.37 \pm 0.01^{\mathrm{d}}$ & $57.73 \pm 0.12^{\mathrm{f}}$ & $15.03 \pm 0.13^{\mathrm{d}}$ & $5.14 \pm 0.03^{\mathrm{b}, \mathrm{c}}$ \\
\hline & 120 & 0.3 & $5.89 \pm 0.03^{\mathrm{c}}$ & $56.30 \pm 0.10^{\mathrm{c}, \mathrm{d}}$ & $14.70 \pm 0.11^{\mathrm{c}}$ & $5.09 \pm 0.03^{\mathrm{a}, \mathrm{b}}$ \\
\hline & & 5.0 & $5.95 \pm 0.02^{\mathrm{c}}$ & $57.65 \pm 0.12^{\mathrm{e}, \mathrm{f}}$ & $14.78 \pm 0.10^{\mathrm{c}}$ & $5.03 \pm 0.03^{\mathrm{a}}$ \\
\hline & 135 & 0.3 & $5.46 \pm 0.04^{b}$ & $55.66 \pm 0.14^{\mathrm{a}}$ & $13.93 \pm 0.12^{\mathrm{b}}$ & $5.37 \pm 0.02^{\mathrm{d}, \mathrm{e}}$ \\
\hline & & 5.0 & $5.51 \pm 0.01^{\mathrm{b}}$ & $56.25 \pm 0.15^{\mathrm{b}, \mathrm{c}}$ & $14.00 \pm 0.11^{\mathrm{b}}$ & $5.35 \pm 0.01^{\mathrm{d}}$ \\
\hline & 150 & 0.3 & $5.25 \pm 0.03^{\mathrm{a}}$ & $56.23 \pm 0.12^{\mathrm{b}, \mathrm{c}}$ & $13.65 \pm 0.08^{\mathrm{a}}$ & $5.46 \pm 0.03^{\mathrm{f}}$ \\
\hline & & 5.0 & $5.22 \pm 0.02^{\mathrm{a}}$ & $56.08 \pm 0.13^{\mathrm{b}}$ & $13.69 \pm 0.11^{\mathrm{a}}$ & $5.42 \pm 0.02^{\mathrm{e}, \mathrm{f}}$ \\
\hline
\end{tabular}

$R H$ relative air humidities, Data are presented as mean \pm SD of three replications; Different lowercase letters for the each cocoa group in the same column indicate statistically significant differences between different roasting conditions according to Tukey's HSD test at $p<0.05$. Different capital letters in the same column indicate statistically significant differences between different cocoa groups according to Tukey's HSD test at $p<0.05$

the effects being dependent on the processing conditions and cocoa origin (Table 1). Total carbohydrate and protein content in all three cocoa groups gradually decreased as the roasting temperature increased from 110 to $150{ }^{\circ} \mathrm{C}$ by $0.3-19.9 \%$ and $3.7-27.1 \%$ of the initial content, respectively. All the investigated types of cocoa beans showed the same response patterns to thermal processing, with beans roasted at $110{ }^{\circ} \mathrm{C}$ exhibiting significantly greater $(p<0.05)$ carbohydrate and protein levels than those treated at higher temperatures. However, it was found that the greatest decrease in the content of carbohydrates caused thermal processing of Trinitario seeds, while the lowest reduction was observed in Criollo samples. Furthermore, the largest and smallest thermally induced reductions in protein content were found for Criollo and Forastero beans, respectively. In addition, lipid concentrations in roasted cocoa beans diverged from the unroasted samples. Thermal processing at $110{ }^{\circ} \mathrm{C}$ caused a slight decline in lipid content in all the analyzed cocoa groups. The most significant $(p<0.05)$ drop in total lipids was observed upon roasting Criollo beans at $120{ }^{\circ} \mathrm{C}$ and $\mathrm{RH}=0.3 \%$, while, in the other cocoa groups, the most pronounced decrease occurred during thermal treatment at $135{ }^{\circ} \mathrm{C}$ and $\mathrm{RH}=0.3 \%$. It was also found that the changes in lipid content depended on the roasting air humidity and were slightly less advanced when the RH was increased from 0.3 to $5.0 \%$. This observation can be explained by the formation of the barrier on the surface of beans by steam contained in air that reduced the access of oxygen into the kernel [32]. Therefore, the lower oxygen concentration can slow down lipid oxidation rates. This conclusion was clearly supported by the fact that main factors responsible 

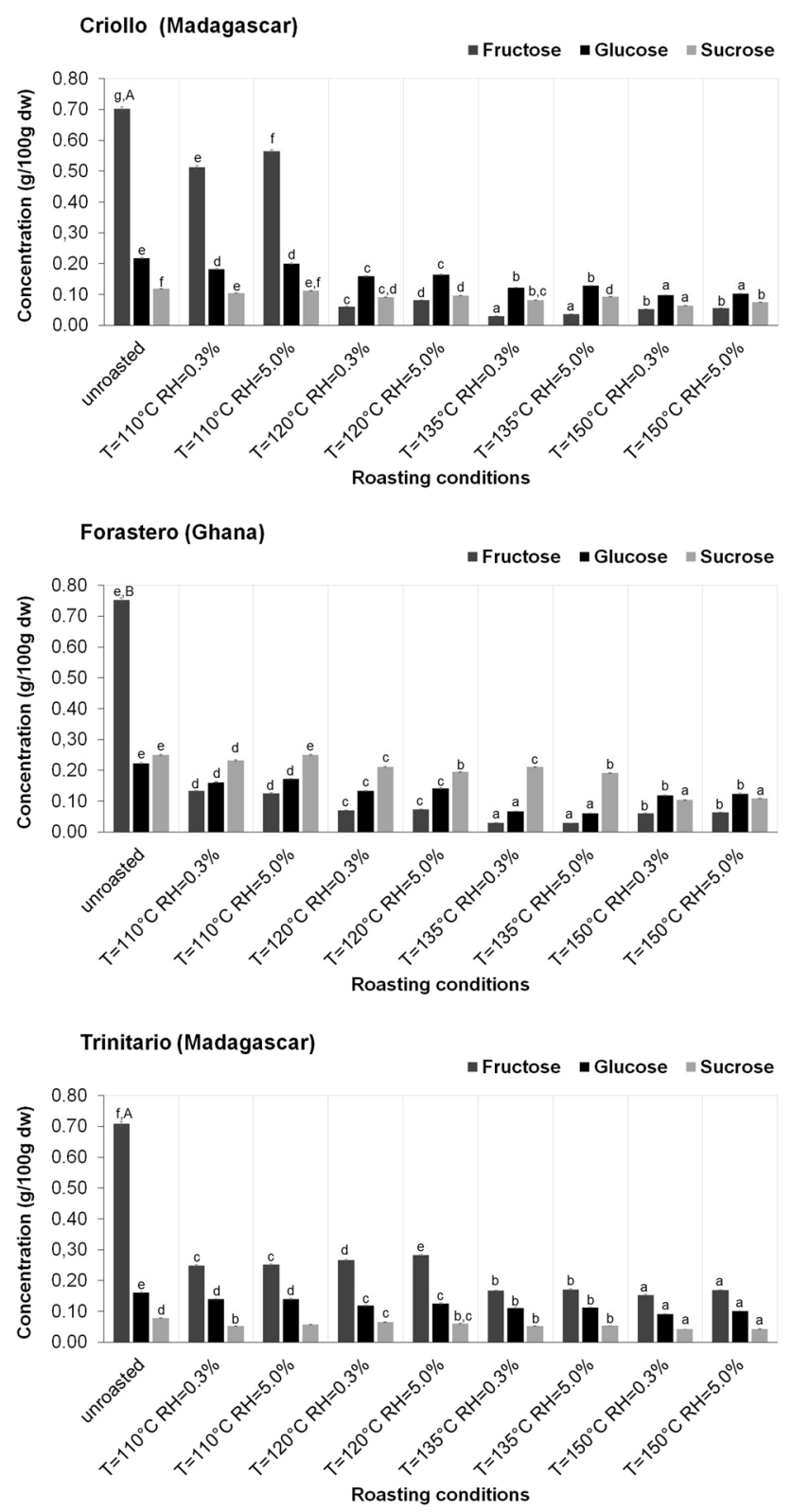

Fig. 1 Free sugar content (g/100 g DW) in cocoa beans, both raw and roasted at different temperatures and relative air humidities, for the following cocoa types: Criollo from Madagascar (a), Forastero from Ghana (b), and Trinitario from Madagascar (c). Results are presented as means \pm SD from triplicate assays. Different lowercase letters for the each cocoa group indicate statistically significant differences between different roasting conditions according to Tukey's HSD test at $p<0.05$. Different capital letters indicate statistically significant differences between different cocoa groups according to Tukey's HSD test at $p<0.05$

for lipids degradation are exposure to oxygen and high temperature during thermal processing [33]. In addition, as it was mentioned earlier, several recent studies indicate that lipid oxidation results in numerous reactive carbonyl compounds participating in carbonyl-amine reactions analogous to the Maillard pathways [21].

Besides differences in total carbohydrate content, there were also significant $(p<0.05)$ variations in the composition of free sugars in cocoa beans of different origins subjected to roasting in various conditions (Fig. 1). A marked decrease in free sugars was noted for almost all the analyzed cocoa samples after thermal treatment at all the tested temperatures. However, thermal processing of Criollo beans at $110{ }^{\circ} \mathrm{C}$ led to only a slight decrease in free sugar concentration (by 15.6-23.0\% of the initial content). The greatest loss of free sugars in all the studied cocoa types (by 69.8-80.5\%) occurred upon roasting at the higher temperatures (135 and $150{ }^{\circ} \mathrm{C}$ ) and lower relative humidity (RH $0.3 \%$ ). The observed decreases in fructose, glucose, and sucrose differed between the analyzed cocoa groups, and, depending on the processing conditions, were within the range of 19.6-95.8\%, $7.9-72.9 \%$, and $3.8-58.6 \%$, respectively. These results are consistent with the data reported in the literature [33]. The roasting-induced decrease in free sugars content in cocoa beans may have occurred due to their thermal degradation with further dehydration and polymerization reactions with reactive intermediates. It may also be assumed that interactions between reducing sugars, such as fructose and glucose, with amino acids and proteins resulting in high-molecularweight Maillard reaction products (MRPs). In the present study, the decline in fructose content was significantly greater $(p<0.05)$ than that of glucose and sucrose. This finding is in accordance with the fact that the reactivity of fructose was greater than glucose during thermal treatment under low-moisture conditions, probably due to its lower melting point and higher molecular mobility compared to glucose. Thus, fructose is more likely to undergo rapid condensation reaction with free amino groups to form the early Maillard reaction intermediates [20,34].

\section{Effect of roasting conditions on phenolic compounds composition of cocoa beans}

As can be seen from Fig. 2, the three studied cocoa types exhibited statistically significant $(p<0.05)$ differences in terms of the 13 phenolic compounds and phenolic/ amino acid conjugates which were identified and quantified in the raw and roasted beans of all origins; these were flavan-3-ols such as epicatechin, catechin, epigallocatechin, procyanidin dimers $\mathrm{B} 1, \mathrm{~B} 2$, and $\mathrm{B} 5$, procyanidin trimer $\mathrm{C} 1$, and cinnamtannin tetramer $\mathrm{A} 2$ as well as $N$-phenylpropenoyl-L-amino acids (NPAs) including $N$-[3', $4^{\prime}$-dihydroxy-(E)-cinnamoyl]-L-aspartic acid (Caff-Asp), $N$-[4'-hydroxy-(E)-cinnamoyl]-L-aspartic acid (pC-Asp), $N$-[3',4'-dihydroxy-(E)-cinnamoyl]-3hydroxy-L-tyrosine (Caff-DOPA), $N$-[3', 4'-dihydroxy(E)-cinnamoyl]-L-tyrosine (Caff-Tyr), and $N$-[4'-hydroxy(E)-cinnamoyl]-L-tyrosine (pC-Tyr). The presence of these compounds in cocoa beans has already been 

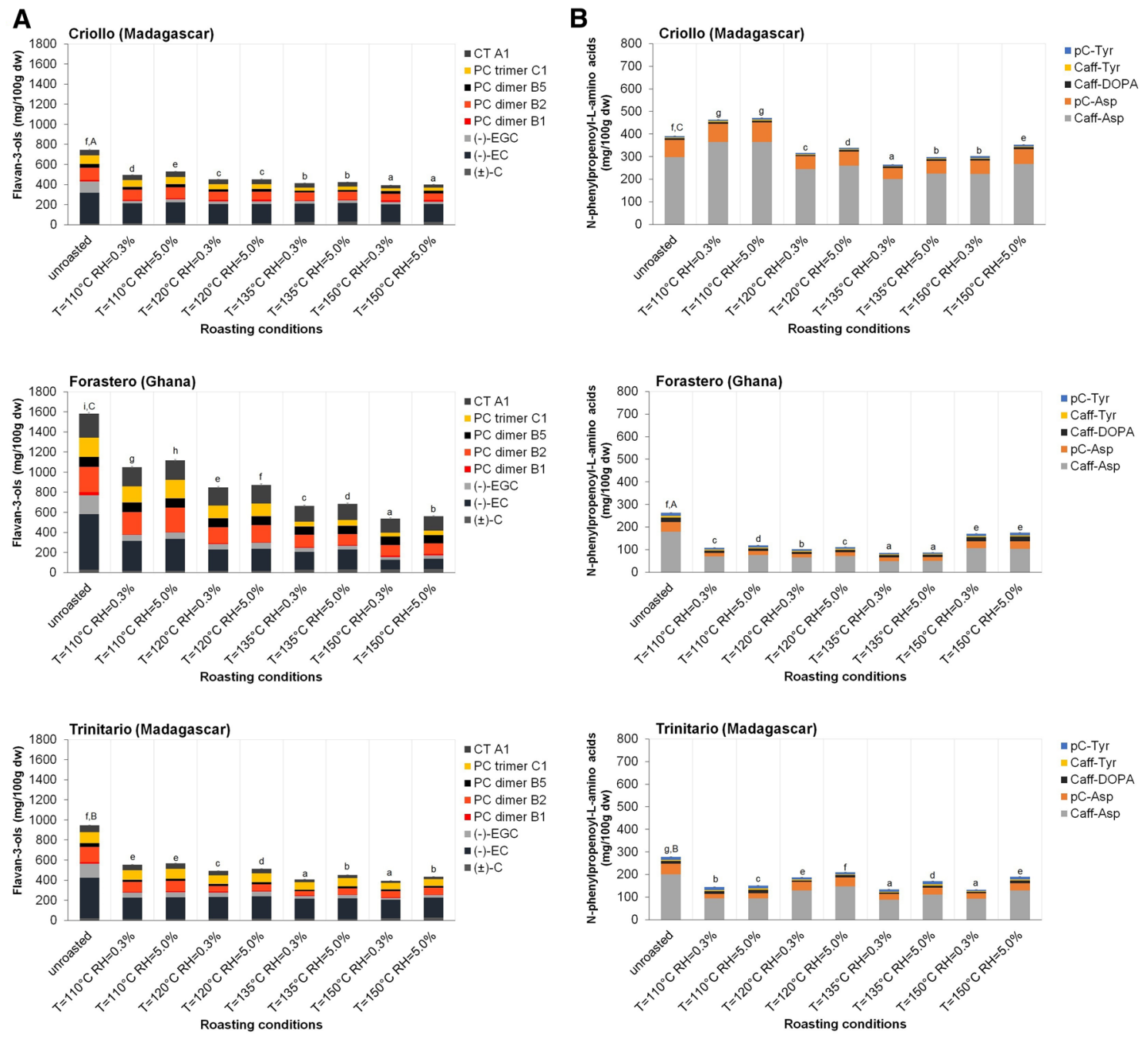

Fig. 2 Content of flavan-3-ols (a) and $\mathrm{N}$-phenylpropenoyl-L-amino acids (b) $(\mathrm{mg} / 100 \mathrm{~g} \mathrm{DW})$ in cocoa beans, both raw and roasted at different temperatures and relative air humidities, for the following cocoa types: Criollo from Madagascar (a), Forastero from Ghana (b), and Trinitario from Madagascar (c). Results are presented as means \pm SD from triplicate assays. Different lowercase letters for

described by other authors [26, 28]. The total amount of the investigated flavan-3-ols within the three cocoa types ranged from $746.77 \mathrm{mg} / 100 \mathrm{~g} \mathrm{DW}$ in raw Criollo beans to $1482.89 \mathrm{mg} / 100 \mathrm{~g}$ DW in Forastero, with the differences being statistically significant $(p<0.05)$. The predominant flavan-3-ol in all studied cocoa beans was epicatechin (305.31-551.76 mg/100 g DW), followed by procyanidin B2 $(120.54-255.11 \mathrm{mg} / 100 \mathrm{~g}$ DW), epigallocatechin (114.03-187.69 mg/100 g DW), procyanidin C1 (84.65-193.08 mg/100 g DW), cinnamtannin A2 (55.96-238.64 mg/100 g DW), procyanidin B5 (40.16-97.16 mg/100 g DW), procyanidin B1 (12.97-31.24 mg/100 g DW), and catechin (11.55-28.22 mg/100 g DW). The present results are,

the each cocoa group indicate statistically significant differences between different roasting conditions according to Tukey's HSD test at $p<0.05$. Different capital letters indicate statistically significant differences between different cocoa groups according to Tukey's HSD test at $p<0.05$

therefore, within the range reported by other authors [26, 35]. Total flavan-3-ol content decreased significantly $(p<0.05)$ after thermal treatment of all studied cocoa types (even at $110{ }^{\circ} \mathrm{C}$ ), and ranged from 393.63 to $1116.07 \mathrm{mg} / 100 \mathrm{~g} \mathrm{DW}$ (Fig. 2A), with the greatest and smallest differences being observed in Forastero and Trinitario samples, respectively. In particular, the roasting process was found to reduce the levels of epicatechin, epigallocatechin, procyanidins $\mathrm{B} 1, \mathrm{~B} 2$, and $\mathrm{B} 5$, procyanidin $\mathrm{C} 1$, cinnamtannin tetramer $\mathrm{A} 2$, and to increase the content of catechin, as compared to the initial levels in unroasted beans. The most pronounced changes in the eight investigated flavan-3-ols for all three studied cocoa beans were observed upon roasting at $150{ }^{\circ} \mathrm{C}$ and $\mathrm{RH}$ 
$0.3 \%$. Several authors have reported considerable roasting-induced reductions in flavan-3-ol content, depending on the cocoa variety and processing conditions [26, 35].

The study also evaluated roasting-induced changes in NPA content. As can be seen from Fig. $2 b$, the sum of these phenolic/amino acid conjugates differed significantly $(p<0.05)$ between raw cocoa beans of different origins, with the highest total NPAs found for Criollo samples and the lowest for the Forastero (the results ranged from 390.24 to $262.56 \mathrm{mg} / 100 \mathrm{~g} \mathrm{DW}$ ). Furthermore, in all studied raw cocoa beans, the most abundant NPA was Caff-Asp (179.45-297.27 mg/100 g DW), followed by pC-Asp (41.78-76.61 mg/100 g DW), Caff-DOPA (6.77-20.55 mg/100 g DW), pC-Tyr (6.52-12.88 mg/100 g DW), and Caff-Tyr (3.07-7.91 mg/100 g DW). The obtained results are similar to the findings previously reported by other authors [28]. In all analyzed cocoa types, NPA levels were affected by roasting. Thermal treatment caused a gradual decrease in total NPAs in almost all analyzed samples (except for Criollo beans roasted at $110^{\circ} \mathrm{C}$ ). This is in agreement with Arlorio et al. [4], who reported a substantial decline in Caff-DOPA levels in roasted cocoa beans. Depending on the cocoa variety and thermal treatment conditions, NPA levels in roasted beans ranged from 67.8 to $120.7 \%$ of the initial value for Criollo to as little as $32.2-66.2 \%$ for Forastero. The sum of the five quantified NPAs in samples subjected to roasting in various conditions was from $84.59 \mathrm{mg} / 100 \mathrm{~g}$ DW for Forastero beans roasted at $135{ }^{\circ} \mathrm{C}$ and $\mathrm{RH}=0.3 \%$ to $470.94 \mathrm{mg} / 100 \mathrm{~g} \mathrm{DW}$ for Criollo beans roasted at $110{ }^{\circ} \mathrm{C}$ and $\mathrm{RH}=5.0 \%$.

The observed changes in flavan-3-ol and phenolic/ amino acid conjugates levels largely depended on process air humidity $(0.3-5.0 \%)$, being much lower at elevated $\mathrm{RH}$. These results may be ascribed to slower degradation of polyphenols during bean roasting at lower temperatures and higher air humidity [26,35]. The content of polyphenols may decrease due to the oxidation of these compounds into quinones and their further degradation, as well as the formation of complexes with proteins, polysaccharides, and other compounds during thermal treatment $[26,35]$. Therefore, the limited oxygen access to nibs upon roasting under high relative air humidity may reduce the extent of oxidative polymerization reactions which normally result in a loss of polyphenols. These findings are consistent with the results reported by Sacchetti et al. [35], who noted that the oxidative polymerization of polyphenols and their interactions with other components of cocoa beans during roasting could also contribute to the development of brown polymeric compounds.

\section{Effect of roasting conditions on the yield of high-molecular-weight compounds}

The yield of the HMW fraction is an interesting index for assessing the possibility to extract and isolate water-soluble HMW compounds with potential industrial applications. As can be seen from Table 1, the yields of HMW material isolated from beans of different origins depended on the cocoa variety and roasting conditions. The amount of HMW compounds in raw beans ranged from 5.35 to $5.91 \mathrm{~g} / 100 \mathrm{~g} \mathrm{DW}$. The HMW content of raw Criollo samples was higher than that of Forastero and Trinitario ones. The discrepancies in the results might be explained by various initial contents of carbohydrates and proteins in beans of different cocoa groups.

Differences in the content of HMW material in beans of the three examined cocoa groups, roasted under different temperature and relative air humidity conditions were significant $(p<0.05)$, with the determined values ranging from 5.03 to $6.04 \mathrm{~g} / 100 \mathrm{~g}$ DW of roasted beans. To the best of our knowledge, this is the first paper reporting on the impact of roasting of cocoa beans on the amount of HMW compounds isolated by dialysis, so the present findings cannot be directly compared with the literature data. However, Bellesia and Tagliazucchi [11] and Pastoriza and Rufián-Henares [36] obtained higher yields of HMW compounds isolated by ultrafiltration from cocoa powder and chocolate, which may be explained by differences in the tested products, as well as in extraction and isolation methods.

The present results show that the cocoa cultivar and thermal processing conditions affect HMW compounds content in cocoa beans. For instance, thermal treatment at 110 and $120^{\circ} \mathrm{C}$ slightly decreased HMW compounds yields (by 3.4-9.8\%) as compared to their initial concentrations in raw samples. The greatest decrease in HMW compounds was caused by roasting at $120^{\circ} \mathrm{C}$ for Criollo and Trinitario beans, and at $110{ }^{\circ} \mathrm{C}$ for Forastero samples. In contrast, after thermal treatment at 135 and $150^{\circ} \mathrm{C}$, the yields of HMW compounds either remained the same or slightly increased. This finding is in agreement with the results reported by Sacchetti et al. [35], who showed that the roasting of cocoa beans to reach approximately $2 \%$ humidity carried out for a short time at a high temperature (18 min at $145{ }^{\circ} \mathrm{C}$ ) gave rise to more HMW melanoidins than processing at lower temperatures for a longer time $\left(62 \mathrm{~min}\right.$ at $\left.125^{\circ} \mathrm{C}\right)$. Furthermore, the amount of HMW material in roasted cocoa beans was found to depend on process air humidity $(\mathrm{RH})$, being slightly higher at $\mathrm{RH}$ $0.3 \%$ than at RH $5.0 \%$ for the same temperatures. Irrespective of the cocoa variety, the highest increase in HMW compound content occurred when the beans were roasted at $150{ }^{\circ} \mathrm{C}$ and $\mathrm{RH} 0.3 \%$. Similar to the results of this study, Bekedam et al. [37] reported that HMW compound yields 
decreased after roasting of green coffee beans to lightroasted beans and then gradually increased upon prolonged thermal treatment.

The decrease of HMW compounds content after thermal treatment at lower temperatures may be explained by the fact that the heat alters the structure of some macromolecules present in raw cocoa bean, including polysaccharides, proteins, and polyphenols [20,38]. According to our results (Table 1; Fig. 1), the observed decline in HMW compounds after roasting at lower temperatures may be ascribed to the thermal decomposition of carbohydrates and proteins. Interestingly, the lower amounts of brown HMW melanoidins detected in cocoa beans roasted at 110 and $120^{\circ} \mathrm{C}$ could be also connected with higher levels of phenolic compounds in those samples as compared to seeds roasted at higher temperatures $\left(135\right.$ and $150{ }^{\circ} \mathrm{C}$ ) (Fig. 2). The previous studies showed that epicatechin, the main phenolic compounds in cocoa beans, may inhibit the early stages of the Maillard reactions by targeting reactive intermediates, such as $\alpha$-dicarbonyls [5, 39]. A recent study also revealed that the presence of polyphenols in cocoa beans reduces the extent of cross-linking of proteins via Maillard reactions upon roasting [5, 38].

On the other hand, increased amounts of HMW material at higher temperatures could be attributed to the formation of brown polymers, such as melanoidins, in the final stage of Maillard reaction [37]. These results are in accordance with the fact that the high temperature and intermediate water activity accelerates the rate of Maillard reactions [5]. As the main constituents of the investigated cocoa beans are lipids, followed by proteins, carbohydrates, and reducing sugars, melanoidins may be formed via amino acids and proteins reacting with reactive carbonyls derived from both lipid peroxidation and reducing sugars. In addition, during cocoa beans roasting, polysaccharides interact with proteins, polyphenols, and MRPs, resulting in the emergence of HMW condensation products [20]. Further oxidation of these products accelerates polymerization reactions between reactive intermediate compounds to form more complex chemical structures [35, 40].

Therefore, we assumed that the formation of HMW Maillard reaction products in cocoa beans requires elevated temperatures and lower relative air humidity. Moreover, the obtained results revealed that, regardless of thermal processing conditions, roasted Criollo beans exhibited higher levels of HMW compounds than samples of the other cocoa varieties, probably due to the higher levels of carbohydrates and lipids and lower content of flavan-3-ols. This hypothesis explains the phenomena of contrary effects of roasting conditions on the content of HMW compounds in different cocoa varieties found in the present study remarkably well.

\section{Effect of roasting conditions on physicochemical properties of high-molecular-weight fractions isolated from cocoa beans}

\section{Chemical composition of high-molecular-weight fractions isolated from cocoa beans}

Figure 3 shows the effects of different roasting conditions on the moisture, protein, and carbohydrate content of HMW fractions isolated from the three studied cocoa varieties. The moisture content of HMW fractions from the studied cocoa beans ranges from 4.40 to $5.99 \%$. Proximal analysis of HMW material from raw beans revealed higher concentrations of proteins $(19.48 \%)$ and carbohydrates $(16.32 \%)$ in Forastero samples as compared to other cocoa groups. HMW fractions from Criollo and Trinitario beans exhibited almost identical protein content (14.91 and $14.55 \%$, respectively), while their carbohydrate levels amounted to 8.08 and $9.70 \%$, respectively.

Thermal treatment of cocoa beans at temperatures in the range of $110-150{ }^{\circ} \mathrm{C}$ caused only minor changes in the moisture content of HMW samples. Our results also show that roasting of all studied cocoa beans over the entire temperature range led to a significant $(p<0.05)$ decrease in the protein and carbohydrate content of HMW material (by $2.6-24.1 \%$ and $6.8-49.3 \%$, respectively), with the changes being also significantly $(p<0.05)$ modified by thermal treatment conditions and cocoa variety. The lowest decrease in protein and carbohydrate concentrations was caused by roasting at $110^{\circ} \mathrm{C}$, while the greatest changes were observed for HMW fractions obtained from almost all the investigated cocoa types roasted at 135 and $150{ }^{\circ} \mathrm{C}$ (except for Trinitario samples). In addition, the concentrations of proteins and carbohydrates were slightly higher at RH $0.3 \%$ than at $\mathrm{RH}$ $5.0 \%$ for the same temperatures. All the observations indicate that HMW melanoidin fractions isolated from roasted cocoa beans were rich in non-carbohydrate and non-protein compounds. We assumed that these results can be explained by the fact that chemically reactive intermediates formed during thermal carbohydrate decomposition, lipid oxidation, as well as polyphenol oxidative degradation are responsible for modifying nucleophilic amino acid side chains of proteins, resulting in the formation of more complex Maillard reaction products [37]. These findings are of relevance, because no data on carbohydrate and protein concentrations in HMW melanoidin fractions isolated from cocoa beans have been reported so far.

\section{Content of free phenolic compounds of high-molecular-weight fractions isolated from cocoa beans}

Several studies have reported that phenolic compounds are incorporated into the structure of HMW melanoidins formed 

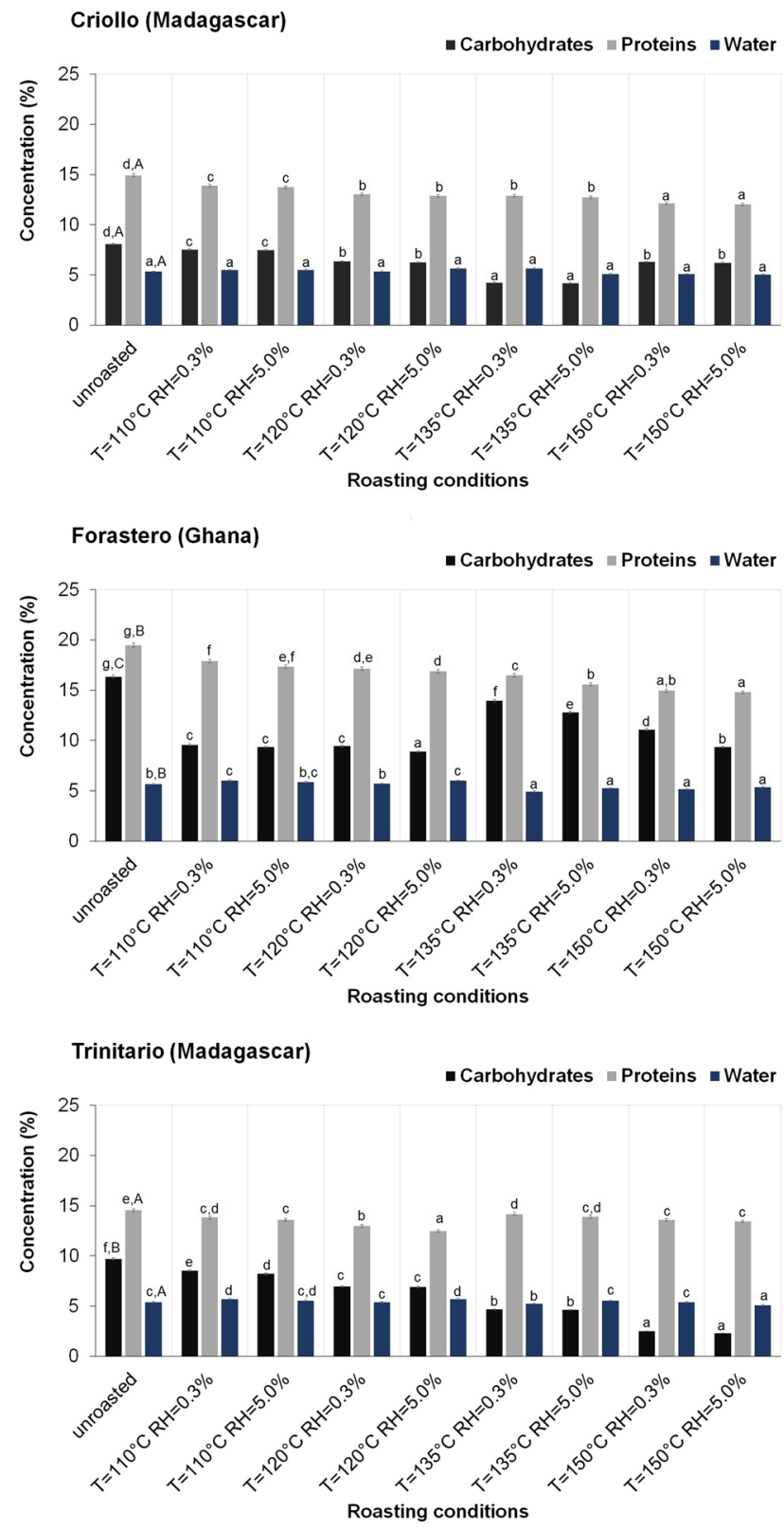

Fig. 3 Proximate composition of HMW fractions isolated from cocoa beans, both raw and roasted at different temperatures and relative air humidities, for the following cocoa types: Criollo from Madagascar (a), Forastero from Ghana (b), and Trinitario from Madagascar (c). Results are presented as means \pm SD from triplicate assays. Different lowercase letters for the each cocoa group indicate statistically significant differences between different roasting conditions according to Tukey's HSD test at $p<0.05$. Different capital letters indicate statistically significant differences between different cocoa groups according to Tukey's HSD test at $p<0.05$

during the heat treatment of coffee, bread, and honey [14, 16, 37]. Therefore, UHPLC-DAD-ESI-MS/MS analysis was performed to study the presence of free phenolic compounds (FPCs) in HMW melanoidin fractions obtained from all the tested cocoa bean samples, whether raw or roasted.
Interestingly, FPCs were found in all of them, which may be partly due to non-covalent adsorption of phenolic compounds by HMW molecules, such as proteins, polysaccharides, and melanoidins, especially through hydrogenbonding and ionic and hydrophobic or other intermolecular interactions [41]. Data on roasting-induced changes in the content of HMW fractions are summarized in Table 2. A total of four phenolic compounds were identified in HMW samples isolated from unroasted and roasted beans of the three investigated cocoa types. The melanoidin fraction contained mainly hydroxycinnamic acid-amino acid conjugates (NPAs) such as Caff-Asp and pC-Asp as well as flavan-3-ols, including epicatechin and procyanidin B2. Interestingly, we found that the share of FPCs in HMW fractions from both unroasted and roasted cocoa beans was rather low, with the total amount of these compounds ranging from 12.88 to $27.07 \mathrm{mg} / 100 \mathrm{~g}$ DW for raw samples. In HMW fractions from unroasted cocoa beans, the most abundant FPC was Caff-Asp, which accounted for 59.5-65.4\% of total FPCs (8.42-17.68 mg/100 g DW). Procyanidin B2 and pC-Asp were the second and third most abundant FPCs, representing $17.1-17.5 \%(2.24-4.60 \mathrm{mg} / 100 \mathrm{~g} \mathrm{DW})$ and $15.3-16.4 \%$ (1.98-4.44 mg/100 g DW) of the total, respectively, whereas epicatechin was found only at low concentrations in HMW fractions from raw cocoa beans representing 1.3-7.2\% $(0.25-1.12 \mathrm{mg} / 100 \mathrm{~g} \mathrm{DW})$. These results suggest that the caffeic acid-amino acid conjugates possess enhanced affinity for proteins and other macromolecules, probably due to the presence of two hydroxyl groups in ortho positions on an aromatic ring of their molecules [42].

Roasting led to substantial changes in the profile and levels of FPCs in HMW fractions. The total amount of these substances varied markedly depending on the cocoa variety and thermal treatment conditions, from 3.75 to $11.17 \mathrm{mg} / 100 \mathrm{~g}$ DW. FPC concentrations tended to decrease (42.8-75.9\%) with increasing temperature, from 110 to $150{ }^{\circ} \mathrm{C}$. In turn, relative air humidity levels $(0.3 \%$ or $5 \%)$ did not have a significant effect $(p>0.05)$ on the content of these compounds. In almost all HMW fractions of roasted cocoa beans, Caff-Asp was the most abundant FPC (26.3-74.1\%, or $0.98-7.52 \mathrm{mg} / 100 \mathrm{~g} \mathrm{DW}$ ), followed by procyanidin B2 $(9.4-46.6 \%$, or $0.78-2.39 \mathrm{mg} / 100 \mathrm{~g} \mathrm{DW})$, pC-Asp (10.9-16.4\%, or $0.41-1.64 \mathrm{mg} / 100 \mathrm{~g} \mathrm{DW})$, and epicatechin (1.3-16.1\%, or $0.15-1.04 \mathrm{mg} / 100 \mathrm{~g} \mathrm{DW})$. It was also found that, similar to the raw beans, the melanoidin fraction of roasted Criollo beans exhibited the highest FPC levels, followed by Forastero and Trinitario. Such differences could be explained by variations in the initial contents of individual phenolic compounds in cocoa beans. Among investigated samples, the highest NPAs levels were found in either raw or roasted Criollo beans (Fig. 2).

In the present work, thermal processing decreased the content of assayable FPCs in HMW fractions probably 
Table 2 Free phenolic compound content (mg/100 g DW) of the HMW fractions of raw and roasted cocoa beans of the Criollo, Forastero, and Trinitario groups originating from various geographical regions

\begin{tabular}{|c|c|c|c|c|c|c|c|}
\hline \multirow[t]{2}{*}{ Cultivars (Country of origin) } & \multicolumn{2}{|c|}{ Roasting conditions } & \multirow[t]{2}{*}{$(-)-E C$} & \multirow[t]{2}{*}{$\mathrm{PC}$ dimer B2 } & \multirow[t]{2}{*}{ Caff-Asp } & \multirow[t]{2}{*}{ pC-Asp } & \multirow[t]{2}{*}{ Total content } \\
\hline & Temp. $\left({ }^{\circ} \mathrm{C}\right)$ & $\mathrm{RH}(\%)$ & & & & & \\
\hline \multirow[t]{9}{*}{ Criollo (Madagascar) } & \multicolumn{2}{|l|}{ Unroasted } & $0.34 \pm 0.02^{\mathrm{d}, \mathrm{B}}$ & $4.60 \pm 0.13^{\mathrm{f}, \mathrm{C}}$ & $17.68 \pm 0.17^{\mathrm{h}, \mathrm{C}}$ & $4.44 \pm 0.13^{\mathrm{f}, \mathrm{C}}$ & $27.07 \pm 0.21^{\mathrm{h}, \mathrm{C}}$ \\
\hline & \multirow[t]{2}{*}{110} & 0.3 & $0.28 \pm 0.01^{\mathrm{c}}$ & $1.73 \pm 0.08^{\mathrm{e}}$ & $7.52 \pm 0.12^{\mathrm{g}}$ & $1.64 \pm 0.08^{\mathrm{e}}$ & $11.17 \pm 0.18^{\mathrm{g}}$ \\
\hline & & 5.0 & $0.28 \pm 0.03^{\mathrm{c}}$ & $1.72 \pm 0.09^{\mathrm{e}}$ & $7.45 \pm 0.13^{\mathrm{f}}$ & $1.62 \pm 0.07^{\mathrm{e}}$ & $11.06 \pm 0.16^{\mathrm{f}}$ \\
\hline & \multirow[t]{2}{*}{120} & 0.3 & $0.25 \pm 0.02^{\mathrm{b}, \mathrm{c}}$ & $1.58 \pm 0.12^{\mathrm{d}}$ & $6.84 \pm 0.14^{\mathrm{d}}$ & $1.49 \pm 0.09^{\mathrm{d}}$ & $10.16 \pm 0.17^{\mathrm{d}}$ \\
\hline & & 5.0 & $0.25 \pm 0.03^{\mathrm{b}, \mathrm{c}}$ & $1.58 \pm 0.10^{\mathrm{d}}$ & $6.96 \pm 0.15^{\mathrm{e}}$ & $1.51 \pm 0.07^{\mathrm{d}}$ & $10.30 \pm 0.15^{\mathrm{e}}$ \\
\hline & \multirow[t]{2}{*}{135} & 0.3 & $0.24 \pm 0.02^{\mathrm{b}}$ & $1.43 \pm 0.12^{\mathrm{c}}$ & $6.15 \pm 0.11^{\mathrm{b}}$ & $1.18 \pm 0.06^{\mathrm{b}}$ & $9.00 \pm 0.14^{\mathrm{c}}$ \\
\hline & & 5.0 & $0.23 \pm 0.01^{\mathrm{a}, \mathrm{b}}$ & $1.38 \pm 0.09^{c}$ & $5.91 \pm 0.12^{\mathrm{a}}$ & $1.13 \pm 0.09^{\mathrm{a}}$ & $8.65 \pm 0.16^{\mathrm{b}}$ \\
\hline & \multirow[t]{2}{*}{150} & 0.3 & $0.21 \pm 0.01^{\mathrm{a}}$ & $0.85 \pm 0.11^{\mathrm{b}}$ & $6.72 \pm 0.10^{\mathrm{c}}$ & $1.29 \pm 0.08^{\mathrm{c}}$ & $9.07 \pm 0.14^{\mathrm{c}}$ \\
\hline & & 5.0 & $0.19 \pm 0.02^{\mathrm{a}}$ & $0.78 \pm 0.07^{\mathrm{a}}$ & $6.17 \pm 0.12^{\mathrm{b}}$ & $1.18 \pm 0.06^{\mathrm{b}}$ & $8.32 \pm 0.17^{\mathrm{a}}$ \\
\hline \multirow[t]{9}{*}{ Forastero (Ghana) } & \multicolumn{2}{|l|}{ Unroasted } & $1.12 \pm 0.04^{\mathrm{e}, \mathrm{C}}$ & $2.73 \pm 0.09^{\mathrm{h}, \mathrm{B}}$ & $9.26 \pm 0.13^{\mathrm{g}, \mathrm{B}}$ & $2.46 \pm 0.12^{\mathrm{d}, \mathrm{B}}$ & $15.58 \pm 0.16^{\mathrm{h}, \mathrm{B}}$ \\
\hline & \multirow[t]{2}{*}{110} & 0.3 & $0.68 \pm 0.02^{\mathrm{b}}$ & $2.39 \pm 0.12^{\mathrm{g}}$ & $4.40 \pm 0.11^{\mathrm{f}}$ & $0.94 \pm 0.07^{\mathrm{c}}$ & $8.41 \pm 0.13^{g}$ \\
\hline & & 5.0 & $0.66 \pm 0.02^{\mathrm{b}}$ & $2.32 \pm 0.02^{f}$ & $4.27 \pm 0.12^{\mathrm{e}}$ & $0.91 \pm 0.06^{\mathrm{c}}$ & $8.17 \pm 0.14^{f}$ \\
\hline & \multirow[t]{2}{*}{120} & 0.3 & $1.04 \pm 0.03^{\mathrm{d}}$ & $2.22 \pm 0.10^{\mathrm{e}}$ & $3.51 \pm 0.10^{\mathrm{d}}$ & $0.85 \pm 0.07^{\mathrm{b}}$ & $7.62 \pm 0.15^{\mathrm{e}}$ \\
\hline & & 5.0 & $1.01 \pm 0.04^{\mathrm{d}}$ & $2.24 \pm 0.09^{\mathrm{e}}$ & $3.49 \pm 0.09^{\mathrm{d}}$ & $0.82 \pm 0.05^{\mathrm{b}}$ & $7.57 \pm 0.16^{\mathrm{e}}$ \\
\hline & \multirow[t]{2}{*}{135} & 0.3 & $0.94 \pm 0.02^{\mathrm{c}}$ & $1.98 \pm 0.07^{\mathrm{d}}$ & $2.64 \pm 0.08^{\mathrm{c}}$ & $0.85 \pm 0.04^{\mathrm{b}}$ & $6.40 \pm 0.17^{\mathrm{d}}$ \\
\hline & & 5.0 & $0.91 \pm 0.03^{\mathrm{c}}$ & $1.92 \pm 0.11^{\mathrm{c}}$ & $2.56 \pm 0.09^{\mathrm{b}}$ & $0.82 \pm 0.06^{\mathrm{b}}$ & $6.22 \pm 0.16^{\mathrm{c}}$ \\
\hline & \multirow[t]{2}{*}{150} & 0.3 & $0.62 \pm 0.02^{\mathrm{a}}$ & $1.80 \pm 0.08^{\mathrm{b}}$ & $1.01 \pm 0.05^{\mathrm{a}}$ & $0.43 \pm 0.03^{\mathrm{a}}$ & $3.86 \pm 0.13^{b}$ \\
\hline & & 5.0 & $0.60 \pm 0.05^{\mathrm{a}}$ & $1.75 \pm 0.09^{\mathrm{a}}$ & $0.98 \pm 0.08^{\mathrm{a}}$ & $0.41 \pm 0.02^{\mathrm{a}}$ & $3.75 \pm 0.14^{\mathrm{a}}$ \\
\hline \multirow[t]{9}{*}{ Trinitario (Madagascar) } & \multicolumn{2}{|l|}{ Unroasted } & $0.25 \pm 0.01^{\mathrm{c}, \mathrm{d}, \mathrm{A}}$ & $2.24 \pm 0.11^{\mathrm{e}, \mathrm{A}}$ & $8.42 \pm 0.14^{\mathrm{e}, \mathrm{A}}$ & $1.98 \pm 0.08^{\mathrm{f}, \mathrm{A}}$ & $12.88 \pm 0.15^{\mathrm{g}, \mathrm{A}}$ \\
\hline & \multirow[t]{2}{*}{110} & 0.3 & $0.24 \pm 0.02^{\mathrm{c}, \mathrm{d}}$ & $1.93 \pm 0.10^{\mathrm{d}}$ & $4.12 \pm 0.11^{\mathrm{d}}$ & $1.09 \pm 0.07^{\mathrm{e}}$ & $7.37 \pm 0.13^{f}$ \\
\hline & & 5.0 & $0.25 \pm 0.01^{\mathrm{c}, \mathrm{d}}$ & $1.90 \pm 0.12^{\mathrm{d}}$ & $4.14 \pm 0.10^{\mathrm{d}}$ & $0.98 \pm 0.06^{\mathrm{d}}$ & $7.27 \pm 0.13^{\mathrm{e}}$ \\
\hline & \multirow[t]{2}{*}{120} & 0.3 & $0.22 \pm 0.01^{\mathrm{b}, \mathrm{c}}$ & $1.75 \pm 0.13^{\mathrm{c}}$ & $3.75 \pm 0.09^{c}$ & $0.92 \pm 0.05^{\mathrm{c}}$ & $6.63 \pm 0.12^{\mathrm{d}}$ \\
\hline & & 5.0 & $0.23 \pm 0.02^{\mathrm{b}, \mathrm{c}}$ & $1.72 \pm 0.10^{\mathrm{b}, \mathrm{c}}$ & $3.76 \pm 0.10^{c}$ & $0.89 \pm 0.06^{\mathrm{c}}$ & $6.61 \pm 0.10^{\mathrm{d}}$ \\
\hline & \multirow[t]{2}{*}{135} & 0.3 & $0.20 \pm 0.01^{\mathrm{b}, \mathrm{c}}$ & $1.69 \pm 0.09^{b}$ & $3.51 \pm 0.08^{\mathrm{b}}$ & $0.83 \pm 0.07^{\mathrm{b}}$ & $6.23 \pm 0.11^{\mathrm{c}}$ \\
\hline & & 5.0 & $0.21 \pm 0.02^{\mathrm{b}, \mathrm{c}}$ & $1.70 \pm 0.08^{\mathrm{b}}$ & $3.47 \pm 0.09^{\mathrm{b}}$ & $0.82 \pm 0.05^{\mathrm{b}}$ & $6.20 \pm 0.14^{\mathrm{c}}$ \\
\hline & \multirow[t]{2}{*}{150} & 0.3 & $0.18 \pm 0.01^{\mathrm{b}}$ & $0.85 \pm 0.11^{\mathrm{a}}$ & $3.21 \pm 0.08^{\mathrm{a}}$ & $0.76 \pm 0.07^{\mathrm{a}}$ & $5.00 \pm 0.10^{\mathrm{b}}$ \\
\hline & & 5.0 & $0.15 \pm 0.02^{\mathrm{a}}$ & $0.84 \pm 0.09^{\mathrm{a}}$ & $3.18 \pm 0.07^{\mathrm{a}}$ & $0.76 \pm 0.08^{\mathrm{a}}$ & $4.93 \pm 0.12^{\mathrm{a}}$ \\
\hline
\end{tabular}

$\mathrm{RH}$, relative air humidities; data are presented as mean \pm SD of three replications. Different lowercase letters for the each cocoa group in the same column indicate statistically significant differences between different roasting conditions according to Tukey's HSD test at $\mathrm{p}<0.05$. Different capital letters in the same column indicate statistically significant differences between different cocoa groups according to Tukey's HSD test at $\mathrm{p}<0.05$

(-)-EC epicatechin, PC dimer, B2 procyanidin dimer B2, Caff-Asp $N$-[3',4'-dihydroxy-(E)-cinnamoyl]-L-aspartic acid, $p C$-Asp $N$-[4'-hydroxy(E)-cinnamoyl]-L-aspartic acid; total contents of the four phenolic compounds including (-)-EC, PC dimer B2, Caff-Asp, and pC-Asp

due to the formation of colored covalent complexes. This is in agreement with the results of other studies, which showed that phenolic compounds can be incorporated into the structure of melanoidins during heat treatment of coffee, bread, and honeys, by either non-covalent and covalent interactions [41]. According to the work of Prigent et al. [43], non-covalent binding ability between hydroxycinnamic acids and proteins decreases with increasing temperature. It is possible that the quinones generated by oxidation of phenolic compounds spontaneously form covalent bonds to functional groups of melanoidins during roasting. The oxidized polyphenols react with nucleophiles, such as amines via Michael-type addition or Schiff base reaction to form either amine-quinone adducts or benzoquinone imines.
Quinones may also react with thiol groups on amino acids, peptides, and proteins to give thiol—quinone adducts [5].

\section{CIE $L^{*} a^{*} b^{*}$ color characteristics of high-molecular-weight fractions isolated from cocoa beans}

Roasting-induced changes in the color of HMW fractions from different cocoa beans were determined using the CIE $L^{*} a^{*} b^{*}$ system consisting of lightness $\left(L^{*}\right)$ and two chromaticity parameters $\left(a^{*}\right.$ and $\left.b^{*}\right)$. The CIE $L^{*} a^{*} b^{*}$ color parameters of HMW fractions from raw beans were dependent on the cocoa variety. The lightness of HMW fractions ranged from 52.97 to 60.32 (Fig. 4), while the redness ( $a^{*}$ ) and yellowness $\left(b^{*}\right)$ were $12.73-13.84$ and $21.00-23.83$, 
respectively. HMW isolates from raw Forastero beans exhibited higher $L^{*}$ values and lower chromaticity values (both $a^{*}$ and $b^{*}$ ) than those from raw Criollo and Trinitario beans, which could be attributed to different concentrations and nature of pigments in HMW fractions, that is, proanthocyanidins, tannin-anthocyanin adducts, and tannin-protein complexes.

Thermal processing of cocoa beans considerably influenced the CIE $L^{*} a^{*} b^{*}$ characteristics of HMW melanoidin


Fig. 4 CIE $L^{*} a^{*} b^{*}$ color parameters of HMW fractions isolated from cocoa beans, both raw and roasted at different temperatures and relative air humidities, for the following cocoa types : Criollo from Madagascar (a), Forastero from Ghana (b), and Trinitario from Madagascar (c). Results are presented as means \pm SD from triplicate assays. Different lowercase letters for the each cocoa group indicate statistically significant differences between different roasting conditions according to Tukey's HSD test at $p<0.05$. Different capital letters indicate statistically significant differences between different cocoa groups according to Tukey's HSD test at $p<0.05$ isolates (Fig. 4). The $L^{*}$ values for all three cocoa varieties decreased significantly (by 6.2 to $23.8 \%$ ) with a temperature increase from 110 to $150^{\circ} \mathrm{C}$ as a result of Maillard reactions and caramelization, which are non-enzymatic browning processes. CIE $L^{*} a^{*} b^{*}$ color parameters were also strongly influenced by roasting conditions. In general, higher temperatures $\left(135\right.$ or $\left.150{ }^{\circ} \mathrm{C}\right)$ and lower air humidity $(\mathrm{RH}=0.3 \%)$ brought about a darker color (lower $L^{*}$ value) in HMW fractions. The lighter color (higher $L^{*}$ ) of the HMW isolates from cocoa beans roasted at RH 5.0\% may be due to a lower rate of oxidation reactions and further condensation of polyphenols. This may be explained by the formation of a protective barrier around the beans by the moisture contained in the air, reducing oxygen penetration.

Our results showed that thermal treatment temperatures between 110 and $150{ }^{\circ} \mathrm{C}$ generally caused a decrease in the $a^{*}$ and $b^{*}$ parameters of HMW fractions isolated from beans of the three cocoa types (except for Trinitario samples roasted at $110^{\circ} \mathrm{C}$ ). While process air humidity also influenced the chromaticity values of the HMW isolates, the effects were less pronounced. In addition, Summa et al. [44] reported that HMW fractions ( $>30$ and $30-10 \mathrm{kDa}$ ) isolated by ultrafiltration from pre-roasted $\left(80-90{ }^{\circ} \mathrm{C}\right.$ for $10 \mathrm{~min})$ and roasted $\left(130-160{ }^{\circ} \mathrm{C}\right.$ for $\left.15-20 \mathrm{~min}\right)$ cocoa beans had significantly $(p<0.05)$ lower CIE $L^{*} a^{*} b^{*}$ values than those obtained from the raw beans. These results are in line with the findings of Nicoli et al. [40], who reported that lower lightness, redness, and yellowness were associated with brown color development during the roasting of coffee beans.

\section{Browning index and fluorescence intensity of high-molecular-weight fractions isolated from cocoa beans}

The effects of roasting conditions on the browning index (absorbance at $420 \mathrm{~nm}$ ) and fluorescence intensity of HMW fractions are shown in Fig. 5. Absorbance measurements at 405 and $420 \mathrm{~nm}$ were done to quantify the brown pigments that were formed in the final stage of Maillard reactions [17]. The present results showed that the intensity of the brown color and fluorescence of HMW fractions from roasted beans was higher than in the case of unroasted beans. The observed increase (by 1.4 up to 78.0\%) in the browning index of HMW fractions from roasted beans depended on the cocoa variety, with the highest changes observed for Trinitario, followed by Criollo and Forastero. In Forastero beans, these changes were statistically significant $(p<0.05)$ only at the higher roasting temperatures. The greatest increment in the browning index of HMW isolates was caused by roasting at $150{ }^{\circ} \mathrm{C}$ for Criollo and Forastero beans and at $135^{\circ} \mathrm{C}$ for Trinitario beans. A comparison of HMW isolates from cocoa beans roasted at different air humidities $(0.3$ and 
Fig. 5 Browning index (absorbance at $420 \mathrm{~nm}$ ) (A) and fluorescence intensity (B) of HMW fractions isolated from cocoa beans, both raw and roasted at different temperatures and relative air humidities, for the following cocoa types: Criollo from Madagascar (a), Forastero from Ghana (b), and Trinitario from Madagascar (c). Results are presented as means $\pm \mathrm{SD}$ from triplicate assays. Different lowercase letters for the each cocoa group indicate statistically significant differences between different roasting conditions according to Tukey's HSD test at $p<0.05$. Different capital letters indicate statistically significant differences between different cocoa groups according to Tukey's HSD test at $p<0.05$
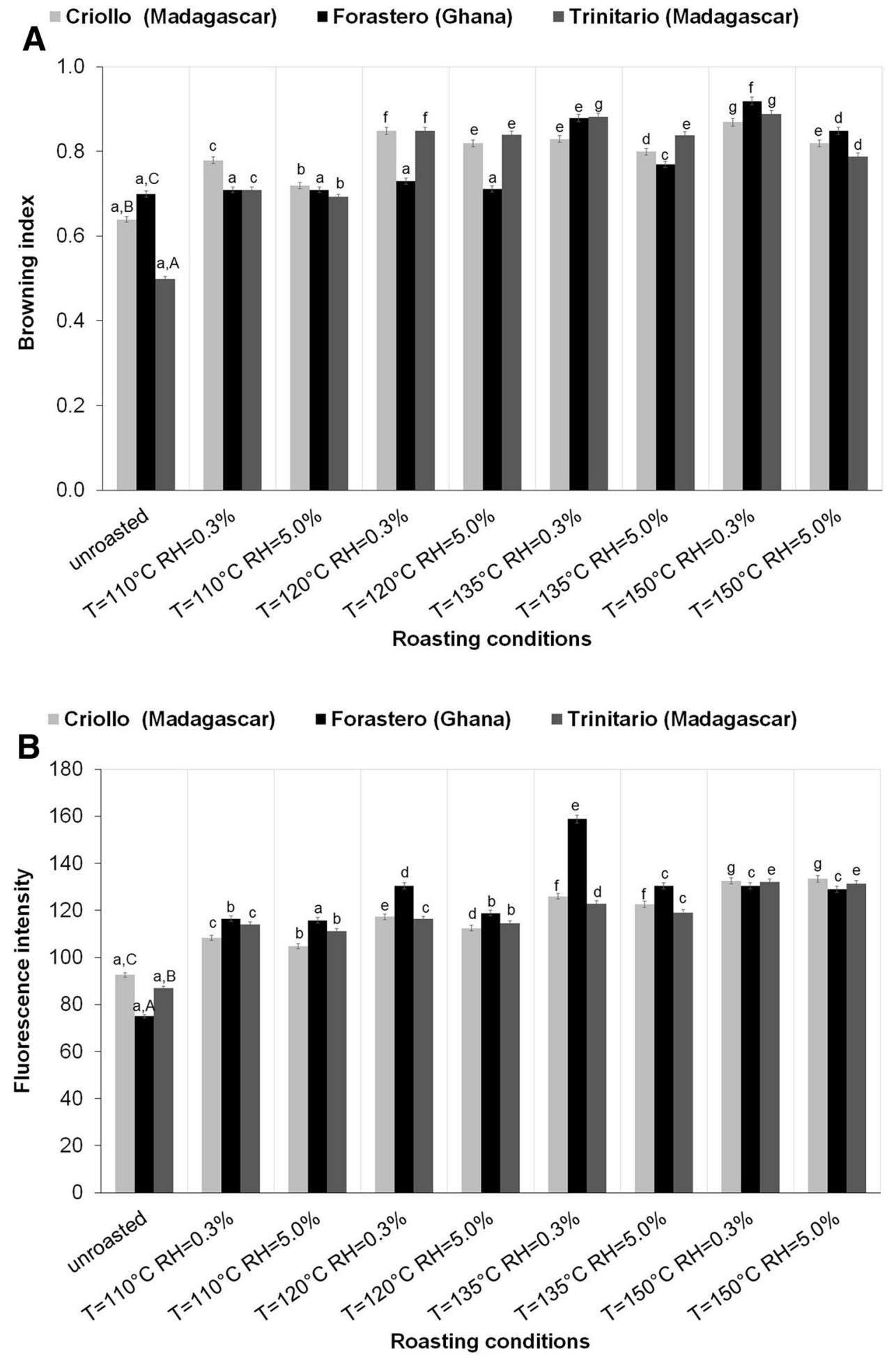

$5.0 \%$ ) revealed that the browning index was slightly higher in samples subjected to thermal processing at lower relative air humidity (RH 0.3\%). In addition, Żyżelewicz et al. [45] reported that melanoidin formation, reflected by a significant ( $p<0.05)$ increase in absorbance at $420 \mathrm{~nm}$, was enhanced by thermal treatment at RH $0.3 \%$ as compared to RH $5.0 \%$.
Aforementioned relation suggests higher browning reaction rates under low RH conditions. The present data also show that the fluorescence intensity of melanoidin fractions from roasted beans increased significantly (13.2-111.7\%, $p<0.05)$ as compared to raw samples. The smallest increments were observed for $110^{\circ} \mathrm{C}$ and $\mathrm{RH} 5.0 \%$, while the 
greatest fluorescence increase was recorded for Criollo and Trinitario varieties after thermal treatment at $150{ }^{\circ} \mathrm{C}$ and $\mathrm{RH}$ $0.3 \%$; in the case of Forastero, the most pronounced increase was observed for $135{ }^{\circ} \mathrm{C}$ and $\mathrm{RH} 0.3 \%$.

The significant increases in the browning and fluorescence intensities of HMW fractions caused by roasting at $110-150{ }^{\circ} \mathrm{C}$ and relative air humidity of 0.3 or $5.0 \%$ were correlated with decreased $L^{*}$ levels $\left(R^{2}=-0.729, p<0.001\right.$; $R^{2}=-0.860, p<0.001$, respectively), which provides evidence that the polymerization reactions between reactive fluorescent intermediates occurring during thermal treatment of cocoa beans contribute to the generation of fluorescent and colored polymers absorbing light at 400-450 $\mathrm{nm}$ [20].

\section{Molecular weight distribution of high-molecular-weight fractions isolated from cocoa beans}

Roasting-induced changes in the molecular weight distribution of HMW cocoa fractions were estimated by high-performance size-exclusion chromatography (HPSEC). HPSECUV chromatograms were recorded at 280 and $420 \mathrm{~nm}$, as is typical for the detection of proteins, polyphenols, and melanoidins in food samples [17]. Unfortunately, the exact molecular weight of melanoidins cannot be determined by HPSEC, because their structures are not fully elucidated. In HPSEC, the analytes are separated according to their molecular size (hydrodynamic volume), with large molecules having shorter retention times (higher hydrodynamic volume) and smaller molecules having longer retention times. However, analytes with the same molecular weight can have different hydrodynamic volumes due to differences in their molecular structure [46]. Despite these disadvantages preventing exact molecular size determination, HPSEC can be a very useful tool for comparing the elution behavior of melanoidin fractions from different samples.

Figure 6 illustrates the effects of temperature and process air humidity on the HPSEC elution profiles of HMW isolates obtained from the studied cocoa beans. The HPSEC chromatograms obtained for raw beans of the three cocoa groups were similar; each displayed a single broad peak in the range of 15.4-21.6 min with few distinguishing features. The result indicated that the molecular weight distribution of HMW fractions obtained from raw cocoa beans ranged from very high $(>100 \mathrm{kDa})$ to low MW compounds $(<17 \mathrm{kDa})$, according to the standard peaks. This high heterogeneity could be related to the complex composition of HMW material obtained from a real food matrix. Based on the above results, it could conclude that HMW fraction of raw cocoa beans consists of a wide range of different compounds, including polymerized forms of proteins, polysaccharides, proanthocyanidin-protein complexes, and products of protein breakdown, generated during fermentation and drying [20]. Similar results were obtained by De Marco, Fischer, and Henle [14] who reported that the molecular weight distribution of HMW fraction (above $10 \mathrm{kDa}$ ) obtained from green coffee beans ranged from 22 to $446 \mathrm{kDa}$.

The HPSEC results demonstrate that roasting induces significant $(p<0.05)$ changes in the molecular weight distribution of melanoidin fractions obtained from cocoa beans (Fig. 6). In addition, the effect of thermal treatment varied between different cocoa groups. The HPSEC chromatograms of HMW fractions isolates from roasted cocoa beans clearly showed a multimodal molecular weight distribution. As can be seen, new distinct peaks appear in the HPSEC chromatograms of the HMW materials from roasted samples. After roasting at 110 and $120^{\circ} \mathrm{C}$, the majority of components of HMW fractions from Forastero and Trinitario beans were eluted between 16.9 and $19.1 \mathrm{~min}$ as three distinct sharp peaks. In turn, the HPSEC chromatograms of HMW fractions from Criollo beans roasted at 110 and $120{ }^{\circ} \mathrm{C}$ showed two broader peaks. The first peak of HPSEC chromatograms gradually shifted to a longer elution time, and the area under this peak increased with roasting temperature (from 110 to $150^{\circ} \mathrm{C}$ ). On the other hand, the areas of the other peaks increase without a significant $(p>0.05)$ change in their position of the HPSEC chromatograms. In general, the shift of the first peak to lower molecular weight and a marked increase in its height observed after roasting may be ascribed to the thermal decomposition of the large molecules, like carbohydrates and proteins, as well as the appearance of colored macromolecules in the HMW fractions. Thermal treatment of all the analyzed cocoa groups at higher temperatures $\left(135\right.$ and $\left.150{ }^{\circ} \mathrm{C}\right)$ led to a further shift and the broadening of the first peak in HPSEC chromatograms of HMW fractions. It was also observed that the ratio of areas under the first and the second peaks changed significantly $(p<0.05)$ between roasting at 135 and $150{ }^{\circ} \mathrm{C}$. At the higher temperature, the area under the first peak significantly increased, while that under the second peak slightly decreased. The other peaks were eluted at almost the same retention times, but the area under these peaks slightly increases as temperature of roasting increased from 110 to $150{ }^{\circ} \mathrm{C}$. The present results show that, although the molecular weight distribution of HMW fractions from cocoa beans roasted at the same temperatures but different air humidities was not significantly different ( $p>0.05)$, the area under the first peak was larger at RH $0.3 \%$. These results suggested that roasting at elevated temperatures $\left(135\right.$ and $\left.150{ }^{\circ} \mathrm{C}\right)$ and lower relative air humidity (RH $0.3 \%$ ) could induce polymerization reactions between colored LMW compounds to form HMW Maillard reaction products absorbing light at $420 \mathrm{~nm}$ [17]. What is noteworthy, for HMW samples of all cocoa varieties, the greatest area under the first peak corresponding to the newly produced brown macromolecules was observed upon roasting at $150{ }^{\circ} \mathrm{C}(49.3-51.2 \%)$. It was found that the amount of newly formed polymers increased with 
Fig. 6 HPSEC chromatograms (420 nm) of HMW fractions isolated from cocoa beans, both raw and roasted at different temperatures and relative air humidities, for the following cocoa types: Criollo from Madagascar (a), Forastero from Ghana (b), and Trinitario from Madagascar (c). The standard protein mix contained proteins of different molecular weights: bovine thyroglobulin, $670 \mathrm{kDa}$; IgA, $300 \mathrm{kDa}$; IgG, $150 \mathrm{kDa}$; ovalbumin, $44 \mathrm{kDa}$; myoglobin, $17 \mathrm{kDa}$


temperature, in line with CIE $L^{*} a^{*} b^{*}$, browning index, and fluorescence measurements (Figs. 4, 5). This finding is also consistent with the work of De Marco, Fischer, and Henle [14] who reported that the average molecular weight of the melanoidin peak increased with the temperature and time of thermal treatment. They also found that the area under this peak grew gradually in the process of roasting, along with increasing absorbance at wavelengths that are generally considered specific to melanoidins.

\section{Conclusions}

The results presented in this study clearly demonstrated that the roasting of cocoa beans at temperature above $135{ }^{\circ} \mathrm{C}$ and relative air humidity of $0.3 \%$ led to significantly greater formation of HMW Maillard reaction products. Our data showed, for the first time, that increasing roasting temperatures and decreasing relative air humidity tended to reduce the content of carbohydrates, proteins, and free phenolics in HMW melanoidins fractions. As a consequence, the observed differences in the CIE $L^{*} a^{*} b^{*}$ color characteristics, browning, and fluorescence intensities, as well as molecular weight distribution between HMW fractions from raw and roasted beans show that roasting may affect the functional properties of these fractions in different ways, depending not only on the cocoa variety, but also on the process temperature and relative air humidity.

Therefore, the results from this study provide a better understanding the effects of roasting conditions on the physicochemical characteristics of HMW melanoidin fractions of different varieties of cocoa beans and show possibility of modifying their content in cocoa-derived products by choosing an appropriate cocoa variety and thermal processing conditions.

Acknowledgements This work was supported by the National Science Centre Poland (Grant number UMO-2012/05/N/NZ9/01399). 


\section{Compliance with ethical standards}

Conflict of interest The authors declare that there are no conflicts of interest.

Compliance with ethics requirements This article does not contain any studies with human or animal subjects.

Open Access This article is distributed under the terms of the Creative Commons Attribution 4.0 International License (http://creativeco mmons.org/licenses/by/4.0/), which permits unrestricted use, distribution, and reproduction in any medium, provided you give appropriate credit to the original author(s) and the source, provide a link to the Creative Commons license, and indicate if changes were made.

\section{References}

1. Kongor JE, Hinneha M, Van deWalle D, Afoakwa EO, Boeckx $P$, Dewettinck K (2016) Factors influencing quality variation in cocoa (Theobroma cacao) bean flavour profile-a review. Food Res Int 82:44-52

2. Oliviero T, Capuano E, Cammerer B, Fogliano V (2009) Influence of roasting on the antioxidant activity and HMF formation of a cocoa bean model systems. J Agric Food Chem 57:147-152

3. Taş NG, Gökmen V (2016) Effect of alkalization on the Maillard reaction products formed in cocoa during roasting. Food Res 89:930-936

4. Arlorio M, Locatelli M, Travaglia F, Coisson J, Grosso E, Minassi A, Appendino G, Martelli A (2008) Roasting impact on the contents of clovamide ( $N$-caffeoyl-L-DOPA) and the antioxidant activity of cocoa beans (Theobroma cacao L.). Food Chem 106:967-975

5. Lund CMN, Ray CA (2017) Control of Maillard reactions in foods: strategies and chemical mechanisms. J Agric Food Chem 65:4537-4552

6. van Durme J, Ingels I, de Winne A (2016) Inline roasting hyphenated with gas chromatography-mass spectrometry as an innovative approach for assessment of cocoa fermentation quality and aroma formation potential. Food Chem 205:66-72

7. Morales FJ, Somoza V, Fogliano V (2012) Physiological relevance of dietary melanoidins. Amino Acid 42(4):1097-1109

8. Mesías M, Delgado-Andrade C (2017) Melanoidins as a potential functional food ingredient. Curr Opin Food Sc 14:37-42

9. Carvalho DO, Correia E, Lopes L, Guido LF (2014) Further insights into the role of melanoidins on the antioxidant potential of barley malt. Food Chem 160:127-133

10. Summa C, McCourt J, Cämmerer B, Fiala A, Probst M, Kun S, Anklam E, Wagner KH (2008) Radical scavenging activity, anti-bacterial and mutagenic effects of cocoa bean Maillard reaction products with degree of roasting. Mol Nutr Food Res 52:342-351

11. Bellesia A, Tagliazucchi D (2014) Cocoa brew inhibits in vitro $\alpha$-glucosidase activity: the role of polyphenols and high molecular weight compounds. Food Res Int 63:439-445

12. Moreira ASP, Nunes FM, Domingues MR, Coimbra MA (2012) Coffee melanoidins: structures, mechanisms of formation and potential health impacts. Food Funct 3:903-915

13. Nunes FM, Coimbra MA (2007) Melanoidins from coffee infusions. Fractionation, chemical characterization, and effect of the degree of roast. J Agric Food Chem 55:3967-3977
14. De Marco LM, Fischer S, Henle T (2011) High molecular weight coffee melanoidins are inhibitors for matrix metalloproteases. J Agric Food Chem 59:11417-11423

15. Kim J-S, Lee Y-S (2009) Study of Maillard reaction products derived from aqueous model systems with different peptide chain lengths. Food Chem 116:846-853

16. Brudzynski K, Miotto D (2011) Honey melanoidins: analysis of the compositions of the high molecular weight melanoidins exhibiting radical-scavenging activity. Food Chem 127:1023-1030

17. Martins SIFS, Van Boekel MJAS (2003) Melanoidins extinction coefficient in the glucose-glycine Maillard reaction. Food Chem 83:135-142

18. Nunes FM, Cruz ACS, Coimbra MA (2012) Insight into the mechanism of coffee melanoidin formation using modified "in bean" models. J Agric Food Chem 60:8710-8719

19. Bertazzo A, Comai S, Mangiarini F, Chen S (2013) In: Watson RR et al (eds) Composition of cacao beans. Chocolate in health and nutrition, nutrition and health. Springer Science + Business Media, LLC

20. Redgwell RJ, Trovato V, Corti D (2003) Cocoa bean carbohydrates: roasting induced changes and polymer interactions. Food Chem 80:511-516

21. Zamora R, Hidalgo FJ (2011) The Maillard reaction and lipid oxidation. Lipid Techn 23(3):59-62

22. Motamayor JC, Lachenaud P, da Silva e Mota JW, Loor R, Kuhn DN et al (2008) Geographic and genetic population differentiation of the Amazonian chocolate tree (Theobroma cacao L). PLoS ONE 3(10):e3311

23. Bekedam EK, Schols HA, Van Boekel MA, Smit G (2006) High molecular weight melanoidins from coffee brew. J Agric Food Chem 54:7658-7666

24. AOAC (2005) Official methods of analysis, 18th edn. Association of Official Analytical Chemists, Washington, D.C

25. Manns D, Deutschle AL, Saake B, Meyer AS (2014) Methodology for quantitative determination of the carbohydrate composition of brown seaweeds (Laminariaceae). RSC Adv 4:25736-25746

26. Oracz J, Nebesny E, Żyżelewicz D (2015) Changes in the flavan3-ols, anthocyanins, and flavanols composition of cocoa beans of different Theobroma cacao L. groups affected by roasting conditions. Eur Food Res Technol 241:663-681

27. Liu J, Gan J, Yu Y, Zhu S, Yin L, Cheng Y (2016) Effect of laboratory-scale decoction on the antioxidative activity of Zhenjiang Aromatic Vinegar: the contribution of melanoidins. J Func Foods 21:5-86

28. Lechtenberg M, Henschel K, Liefländer-Wulf U, Quandt B, Hensel (2012) Fast determination of $N$-phenylpropenoyl-l-amino acids (NPA) in cocoa samples from different origins by ultra-performance liquid chromatography and capillary electrophoresis. Food Chem 135:1676-1684

29. Rufián-Henares JA, Morales FJ (2007) Functional properties of melanoidins: In vitro antioxidant, antimicrobial and antihypertensive activities. Food Res Int 40:995-1002

30. Dong S, Panya A, Zeng M, Chen B, McClements DJ, Decker EA (2012) Characteristics and antioxidant activity of hydrolyzed $\beta$-lactoglobulin-glucose Maillard reaction products. Food Res Int 46:55-61

31. Efraim P, Pires JL, Garcia AO, Grimaldi R, Luccas V, PezoaGarcia NH (2013) Characteristics of cocoa butter and chocolates obtained from cocoa varieties grown in Bahia, Brazil. Eur Food Res Technol 237:419-428

32. Krysiak W (2011) Effects of convective and microwave roasting on the physicochemical properties of cocoa beans and cocoa butter extracted from this material. Grasas Aceites 62:467-478

33. Choe E, Min DB (2006) Mechanisms and factors for edible oil oxidation. Comp Rev Food Sci Food Safety 5:169-186 
34. Gokmen V, Senyuva HZ (2008) In: Gilbert J, Senyuva HZ (eds) Bioactive compounds in foods. Blackwell Publishing Ltd., Oxford

35. Sacchetti G, Ioannone F, De Gregorio M, Di Mattia C, Serafini M, Mastrocola D (2016) Non enzymatic browning during cocoa roasting as affected by processing time and temperature. J Food Eng 169:44-52

36. Pastoriza S, Rufián-Henares JA (2014) Contribution of melanoidins to the antioxidant capacity of the Spanish diet. Food Chem 164:438-445

37. Bekedam EK, Loots MJ, Schols HA, Van Boekel MA, Smit G (2008) Roasting effects on formation mechanisms of coffee brew melanoidins. J Agric Food Chem 56:7138-7145

38. Jumnongpon R, Chaiseri S, Hongsprabhas P, Healy J, Meade SJ, Gerrard JA (2012) Cocoa protein crosslinking using Maillard chemistry. Food Chem 134:375-380

39. Totlani VM, Peterson DG (2005) Reactivity of epicatechin in aqueous glycine and glucose Maillard reaction models: quenching of $\mathrm{C} 2, \mathrm{C} 3$, and $\mathrm{C} 4$ sugar fragments. J Agric Food Chem 53:4130-4135

40. Nicoli MC, Anese M, Manzocco L, Lerici CR (1997) Antioxidant properties of coffee brews in relation to the roasting degree. LWT Food Sci Technol 30:292-297

41. Coelho C, Ribeiro M, Cruz AC, Domingues MR, Coimbra MA, Bunzel M, Nunes FM (2014) Nature of phenolic compounds in coffee melanoidins. J Agric Food Chem 62(31):7843-7853
42. Wang S, Suh JH, Hung WL, Zheng X, Wang Y, Ho CT (2018) Use of UHPLC-TripleQ with synthetic standards to profile antiinflammatory hydroxycinnamic acid amides in root barks and leaves of Lycium barbarum. J Food Drug Anal 26(2):572-582

43. Prigent SV, Gruppen H, Visser AJ, Van Koningsveld GA, De Jong GA, Voragen AG (2003) Effects of non-covalent interactions with 5-O-caffeoylquinic acid (chlorogenic acid) on the heat denaturation and solubility of globular proteins. J Agric Food Chem 51(17):5088-5095

44. Summa C, Raposo FC, McCourt J, Lo Scalzo R, Wagner KH, Elmadfa I, Anklam E (2006) Effect of roasting on the radical scavenging activity of cocoa beans. Eur Food Res Technol 222:368-375

45. Żyżelewicz D, Krysiak W, Nebesny E, Budryn G (2014) Application of various methods for determination of the color of cocoa beans roasted under variable process parameters. Eur Food Res Technol 238:549-563

46. Hong P, Koza S, Bouvier ESP (2012) Size-exclusion chromatography for the analysis of protein biotherapeutics and their aggregates. J Liq Chromatogr Relat Technol 35(20):2923-2950 